\title{
Freshwater conservation assessments in (semi-)arid regions: Testing river intermittence and buffer strategies using freshwater mussels (Bivalvia, Unionida) in Morocco
}

\author{
André Gomes-dos-Santos ${ }^{\mathrm{a}, \mathrm{i}, *}$, Elsa Froufe ${ }^{\mathrm{a}}$, Duarte V. Gonçalves ${ }^{\mathrm{a}}$, Ronaldo Sousa ${ }^{\mathrm{b}}$, Vincent Priéc ${ }^{\text {, }}$ \\ Mohamed Ghamizi ${ }^{\mathrm{d}}$, Hassan Benaissa ${ }^{\mathrm{d}}$, Simone Varandas ${ }^{\mathrm{e}}$, Amílcar Teixeira ${ }^{\mathrm{f}}$, \\ Manuel Lopes-Lima ${ }^{\text {a,g,h }}$
}

\begin{abstract}
${ }^{\text {a }}$ CIIMAR/CIMAR - Interdisciplinary Centre of Marine and Environmental Research, University of Porto, Terminal de Cruzeiros do Porto de Leixões, Avenida General Norton de Matos, S/N, P 4450-208 Matosinhos, Portugal

${ }^{\mathrm{b}}$ CBMA - Centre of Molecular and Environmental Biology, Department of Biology, University of Minho, Campus Gualtar, 4710-057 Braga, Portugal

${ }^{c}$ Muséum National d'Histoire Naturelle, Département Systématique et Evolution, ISyEB (UMR 7205 CNRS/UPMC/MNHN/EPHE), 43, Rue Cuvier, 75231 Paris, France

${ }^{\mathrm{d}}$ Muséum d'Histoire Naturelle de Marrakech, Université Cadi Ayyad, Faculté des Sciences Semlalia; LHEACG, B.P. 2390, Marrakech, Morocco

${ }^{\mathrm{e}}$ CITAB-UTAD - Centre for Research and Technology of Agro-Environment and Biological Sciences, University of Trás-os-Montes and Alto Douro, Forestry Department, Apartado 1013, 5001-811 Vila Real, Portugal

${ }^{\mathrm{f}}$ CIMO-ESA-IPB - Mountain Research Centre, School of Agriculture, Polytechnic Institute of Bragança, Campus de Santa Apolónia, Apartado 1172, 5301-854 Bragança, Portugal

${ }^{\mathrm{g}}$ CIBIO/InBIO - Research Center in Biodiversity and Genetic Resources, Universidade do Porto, Campus Agrário de Vairão, Rua Padre Armando Quintas, 4485-661 Vairão, Portugal

${ }^{\mathrm{h}}$ IUCN SSC Mollusc Specialist Group, c/o IUCN, David Attenborough Building, Pembroke St., Cambridge, England, United Kingdom of Great Britain and Northern Ireland
\end{abstract}

${ }^{\mathrm{i}}$ Department of Biology, Faculty of Sciences, University of Porto, Rua do Campo Alegre 1021/1055, Porto, Portugal

A R T I C L E I N F O

\section{Keywords:}

Unionida

Biogeography

River desiccation

North Africa

\begin{abstract}
A B S T R A C T
The IUCN Red List assessments are essentially based on population trends and range, namely Area of Occupancy (AOO) and Extent of Occupancy (EOO). Range estimations are based on fixed grids, but this is likely inappropriate for species living in river networks. Furthermore, AOO and EOO are measured using the whole hydrographic network, therefore disregarding temporary sections, which is particularly problematic in arid and semi-arid regions. Here we mapped the permanent hydrographic network of Morocco using satellite imagery, complemented with field surveys to collect samples for molecular analyses of the five freshwater mussel species present and assess their distribution. The phylogeographic patterns are described for each species and used to identify priority areas and evolutionary significant units for conservation. Permanent hydrographic river sections represent only $18.3 \%$ of the whole hydrographic network. A north-to-south gradient of genetic diversity, species richness and distribution range was found, being coherent with water availability and river intermittence. Isolated evolutionary units were detected in southern basins that should also receive particular attention in conservation planning. We propose the mean river width multiplied by the extent of the river network as the best and the most adequate way to estimate both EOO and AOO. Given the worldwide degradation of freshwater systems and biodiversity, an accurate (re)assessment of species conservation status supported with maps of intermittent water bodies will be essential for prioritizing and guiding conservation actions and management plans, especially in arid and semi-arid regions.
\end{abstract}

\section{Introduction}

Freshwater ecosystems support disproportionally high biodiversity when considering the respective occupied earth surface (around $0.8 \%$ )
(Balian et al., 2008). This is due to their physical and spatial structure, which favours isolation and impairs long distance or cross-basin dispersal, resulting in high levels of endemism and speciation (Strayer and Dudgeon, 2010). Freshwater ecosystems provide a wide range of

\footnotetext{
* Corresponding author at: CIIMAR/CIMAR - Interdisciplinary Centre of Marine and Environmental Research, University of Porto, Terminal de Cruzeiros do Porto de Leixões, Avenida General Norton de Matos, S/N, P 4450-208 Matosinhos, Portugal.

E-mail address: andrepousa64@gmail.com (A. Gomes-dos-Santos).
} 
services (Carpenter et al., 2011; Vaughn, 2018); however, the growing human population and agriculture and industrial development have enhanced the need for water resources and increased the pressure upon freshwater systems (Dudgeon et al., 2006; Reid et al., 2019).

Studies on freshwater biodiversity have gathered increasing interest in the last decades, but most tend to favour vertebrates over invertebrates (Lydeard et al., 2004; Cardoso et al., 2011a), even though the latter usually dominate in abundance and biomass (Cardoso et al., 2011a). Freshwater bivalves of the order Unionida, Grey, 1854 are globally spread organisms, playing fundamental roles in ecosystem functions and services such as cycling of nutrients, matter and energy, water purification, bioturbation, among others (Vaughn and Hakenkamp, 2001; Spooner et al., 2013; Lopes-Lima et al., 2017; Vaughn, 2018). Despite all of this, freshwater mussels are globally threatened and many populations are in pronounced decline (Strayer et al., 2004; Graf and Cummings, 2007; Lopes-Lima et al., 2014b, 2018). Recent efforts have been implemented to better understand and conserve this group (Lopes-Lima et al., 2014a, 2014b, 2018), but there is still much to be done (see Ferreira-Rodríguez et al., 2019). Freshwater mussels are considered "permanent refugial organisms" (Sheldon et al., 2010), meaning they have limited dispersal abilities even under flow conditions, and are restricted to areas where water availability is permanent across many years. This makes freshwater mussels highly vulnerable to alterations in flow regime.

The Mediterranean region is one of the world's major hotspots of biodiversity and conservation priorities (Myers et al., 2000). The region's complex geo-climatic history has been proposed as the main factor shaping the phylogeographic patterns of many taxa (Myers et al., 2000; Husemann et al., 2012, 2014), including freshwater mussels (e.g. Araujo et al., 2009, 2010, 2016; Khalloufi et al., 2011; Reis et al., 2013; Froufe et al., 2014, 2016a, 2016b). In the more arid areas, the varying permanence of water likely assumed a preponderant role on population persistence and dynamics. North-African countries, such as Morocco, are particularly vulnerable to climate change and prone to extreme climate events (Schilling et al., 2012; Schyns and Hoekstra, 2014). Droughts are becoming longer and more frequent (Schilling et al., 2012); therefore, intermittent rivers will play an even larger role in ecosystem management. This creates an urgent need for proper data and suitable conservation strategies, but also an opportunity to study and develop a framework for a globally, highly relevant and expanding type of landscape.

Even though urgent conservation planning is needed, basic data like the diversity and distribution of freshwater mussel species is often outdated or even absent, particularly in North Africa (Graf and Cummings, 2011). Moroccan freshwater mussels have been the focus of some studies during the 20th century (Pallary, 1918, 1928; Van Damme, 1984; Mandhal-Barth, 1988; Daget, 1998), but only in the last decade was it possible to start tackling the uncertainties regarding current distributions and taxonomy, mostly due to molecular approaches (Araujo et al., 2009, 2010; Khalloufi et al., 2011; Froufe et al., 2016a, 2016b; Sousa et al., 2016, 2018). Presently, there are five recognised native freshwater mussel species in Morocco: four from family Unionidae Rafinesque 1820: Anodonta sp. (Lamarck, 1799), Potomida littoralis (Cuvier, 1798), Unio gibbus (Spengler, 1793) and Unio foucauldianus (Pallary, 1936); and one from family Margaritiferidae Henderson 1929 (1910): Pseudunio marocanus (Pallary, 1918). With the exception of the Anodonta sp., the taxonomic status of all Moroccan species has been recently tested and validated (Araujo et al., 2009, 2016; Froufe et al., 2016a, 2016b). The current distribution of all five species is poorly known and/or outdated, since almost all species have apparently suffered great declines over their range in the last decades (Araujo et al., 2009, 2010; Froufe et al., 2016a, 2016b; Sousa et al., 2016, 2018).

Intermittent rivers are among the most endangered of freshwater ecosystems. They are characterized by natural periodical interruption of flow and drastic fluctuations in the extent of freshwater habitat
(Stanley et al., 1997; Sheldon et al., 2010). These rivers constitute more than half of the length of the global river network, and are increasing in number and length in response to climate change, land-use alteration, and water abstraction (Datry et al., 2014; Datry et al., 2017). Despite significant biodiversity (e.g. Kingsford et al., 1998) and ecosystems services generated (e.g. nutrient cycling and groundwater renewal) (Sophocleous, 2002; Bernhardt and Palmer, 2011), the conservation significance of intermittent rivers is generally ignored (Leigh et al., 2016). They usually lack suitable management practices, protective policies and legislation, which are generally designed for perennial systems (Datry et al., 2014; Leigh et al., 2016). Consequently, efficient management will require a better understanding of the dynamics of shifting between lotic, lentic and dry conditions, and the improvement of river mapping (Datry et al., 2014, 2016; Leigh et al., 2016, 2019).

The increasing pressure on freshwater systems has a direct impact on already declining freshwater diversity (Strayer and Dudgeon, 2010; Carpenter et al., 2011; Reid et al., 2019). Correctly assigning conservation status of species is essential to effectively prioritize and guide management plans. The Red List proposed by International Union for Conservation of Nature (IUCN) is the most widely used framework for this important purpose (IUCN, 2001). For IUCN red-listing, categories are attributed according to five standard criteria, one of which (B) evaluates species extinction risk using its distribution area in two parameters: the area of occupancy (AOO, area occupied by a species) and extent of occurrence (EOO, region encompassing all possible presence sites, usually a minimum-convex polygon or a $\alpha$-hull). These parameters are calculated using a $2 \times 2 \mathrm{~km}$ square grid following IUCN guidelines (IUCN, 2001). This strategy may be suitable to fit terrestrial organisms, but is likely misleading for freshwater taxa, particularly when their distributions are limited to water bodies.

Given the urgency of having realistic river network maps, of optimizing conservation status assessments of freshwater organisms, and of updating the distribution, diversity and conservation status of freshwater mussel species, the aims of this study were to: i) map permanent river segments of the Moroccan hydrographic network; ii) update the current distribution and phylogeographic knowledge of the five species of Unionida present in Morocco, iii) clarify the taxonomic status of the Moroccan Anodonta sp.; iv) develop a more realistic approach for calculating the AOO and EOO to efficiently assign freshwater species conservation status; and v) use all this information to identify key areas of conservation for freshwater mussels in Morocco.

\section{Material and methods}

\subsection{Sample and data collection}

A total of 189 sites were surveyed across the country, encompassing all major river basins in Morocco. The surveys were carried between May 2013 and August 2018. Many different habitat types were assessed including permanent and temporary rivers and streams, and even artificial irrigation channels and dam reservoirs. The assessment considered previous information on the distribution of freshwater mussels in Morocco (Pallary, 1918, 1923, 1928; Van Damme, 1984; MandhalBarth, 1988; Daget, 1998). At each site, the search was conducted by wading, diving and hand-sampling following the rapid bioassessment methods for freshwater bivalves described by Cummings et al. (2016). The coordinates of each sampling site were recorded using GPS. Distribution data collected during the present study was supplemented by bibliographical data (Araujo et al., 2009, 2010, 2016; Froufe et al., 2016a, 2016b; Sousa et al., 2016, 2018). All collected individuals were morphologically identified on site and a small tissue snip was collected from each specimen following a non-lethal protocol (Naimo et al., 1998) for genetic analyses (Table 1). The freshwater mussels were then returned to their original positions.

In total, 153 individuals were collected for molecular analyses across Morocco (7 P. marocanus, 12 Anodonta sp., 19 P. littoralis, $75 U$. 
Table 1

List of all sampled individual: species; codes; population; river basin and respective GenBank accession codes.

\begin{tabular}{|c|c|c|c|c|c|}
\hline Code & Species & Population & River Basin & Country & GenBank \\
\hline BIV 2000 & Anodonta anatina & Oum Er-Rbia & Oum Er-Rbia & Morocco & MK733420 \\
\hline BIV 2001 & Anodonta anatina & Oum Er-Rbia & Oum Er-Rbia & Morocco & MK733421 \\
\hline BIV 2002 & Anodonta anatina & Oum Er-Rbia & Oum Er-Rbia & Morocco & MK733422 \\
\hline BIV 2003 & Anodonta anatina & Oum Er-Rbia & Oum Er-Rbia & Morocco & MK733423 \\
\hline BIV 2004 & Anodonta anatina & Oum Er-Rbia & Oum Er-Rbia & Morocco & MK733424 \\
\hline BIV 2006 & Anodonta anatina & Oum Er-Rbia & Oum Er-Rbia & Morocco & MK733425 \\
\hline BIV 2580 & Anodonta anatina & Loukos & Loukos & Morocco & MK733426 \\
\hline BIV 2581 & Anodonta anatina & Loukos & Loukos & Morocco & MK733427 \\
\hline BIV 2582 & Anodonta anatina & Loukos & Loukos & Morocco & MK733428 \\
\hline BIV 2583 & Anodonta anatina & Loukos & Loukos & Morocco & MK733429 \\
\hline BIV 2584 & Anodonta anatina & Loukos & Loukos & Morocco & MK733430 \\
\hline BIV 2585 & Anodonta anatina & Loukos & Loukos & Morocco & MK733431 \\
\hline BIV2635 & Pseudunio marocanus & Bouhlou & Bouhlou, Sebou & Morocco & MK733432 \\
\hline BIV2640 & Pseudunio marocanus & Bouhlou & Bouhlou, Sebou & Morocco & MK733433 \\
\hline BIV2641 & Pseudunio marocanus & Bouhlou & Bouhlou, Sebou & Morocco & MK733434 \\
\hline BIV 2642 & Pseudunio marocanus & Bouhlou & Bouhlou, Sebou & Morocco & MK733435 \\
\hline BIV2643 & Pseudunio marocanus & Bouhlou & Bouhlou, Sebou & Morocco & MK733436 \\
\hline BIV2644 & Pseudunio marocanus & Bouhlou & Bouhlou, Sebou & Morocco & MK733437 \\
\hline BIV2645 & Pseudunio marocanus & Bouhlou & Bouhlou, Sebou & Morocco & MK733438 \\
\hline BIV2035 & Potomida littoralis & Douar Laalaoua Bridge & Oum-Er-Rbia & Morocco & MK733439 \\
\hline BIV2037 & Potomida littoralis & Douar Laalaoua Bridge & Oum-Er-Rbia & Morocco & MK733440 \\
\hline BIV2038 & Potomida littoralis & Douar Laalaoua Bridge & Oum-Er-Rbia & Morocco & MK733441 \\
\hline BIV2039 & Potomida littoralis & Douar Laalaoua Bridge & Oum-Er-Rbia & Morocco & MK733442 \\
\hline BIV2040 & Potomida littoralis & Douar Laalaoua Bridge & Oum-Er-Rbia & Morocco & MK733443 \\
\hline BIV2041 & Potomida littoralis & Douar Laalaoua Bridge & Oum-Er-Rbia & Morocco & MK733444 \\
\hline BIV0626 & Potomida littoralis & Tilougass & Amaghouss, Massa & Morocco & MK733445 \\
\hline BIV2536 & Potomida littoralis & Dar Bel Amri & Beth, Sebou & Morocco & MK733446 \\
\hline BIV 2541 & Potomida littoralis & Dar Bel Amri & Beth, Sebou & Morocco & MK733447 \\
\hline BIV 2538 & Potomida littoralis & Dar Bel Amri & Beth, Sebou & Morocco & MK733448 \\
\hline BIV3223 & Potomida littoralis & Zewiherate Taoughilt & Ouergha, Sebou & Morocco & MK733449 \\
\hline BIV3224 & Potomida littoralis & Zewiherate Taoughilt & Ouergha, Sebou & Morocco & MK733450 \\
\hline BIV3225 & Potomida littoralis & Zewiherate Taoughilt & Ouergha, Sebou & Morocco & MK733451 \\
\hline BIV3194 & Potomida littoralis & Tetouan & Hajera, Martil & Morocco & MK733452 \\
\hline BIV3195 & Potomida littoralis & Tetouan & Hajera, Martil & Morocco & MK733453 \\
\hline BIV3196 & Potomida littoralis & Tetouan & Hajera, Martil & Morocco & MK733454 \\
\hline BIV 3197 & Potomida littoralis & Tetouan & Hajera, Martil & Morocco & MK733455 \\
\hline BIV3198 & Potomida littoralis & Tetouan & Hajera, Martil & Morocco & MK733456 \\
\hline BIV3199 & Potomida littoralis & Tetouan & Hajera, Martil & Morocco & MK733457 \\
\hline UD636 & Unio foucauldianus & Kenitra & Mda & Morocco & MK733458 \\
\hline UD639 & Unio foucauldianus & Kenitra & Mda & Morocco & MK733459 \\
\hline UD638 & Unio foucauldianus & Kenitra & Mda & Morocco & MK733460 \\
\hline BIV663 & Unio foucauldianus & Douar Chebabate & Abiod, Sebou & Morocco & MK733461 \\
\hline BIV664 & Unio foucauldianus & Douar Chebabate & Abiod, Sebou & Morocco & MK733462 \\
\hline BIV665 & Unio foucauldianus & Douar Chebabate & Abiod, Sebou & Morocco & MK733463 \\
\hline BIV3229 & Unio foucauldianus & Bouhlou & Bouhlou, Sebou & Morocco & MK733464 \\
\hline BIV3230 & Unio foucauldianus & Bouhlou & Bouhlou, Sebou & Morocco & MK733465 \\
\hline BIV805 & Unio foucauldianus & Sidi Said Maachou & Oum Er-Rbia & Morocco & MK733466 \\
\hline BIV806 & Unio foucauldianus & Sidi Said Maachou & Oum Er-Rbia & Morocco & MK733467 \\
\hline BIV602 & Unio foucauldianus & Guelmim & Noun & Morocco & MK733468 \\
\hline BIV603 & Unio foucauldianus & Guelmim & Noun & Morocco & MK733469 \\
\hline BIV614 & Unio foucauldianus & Tilougass & Amaghouss, Massa & Morocco & MK733470 \\
\hline BIV615 & Unio foucauldianus & Tilougass & Amaghouss, Massa & Morocco & MK733471 \\
\hline BIV2509 & Unio foucauldianus & Oumnass & Nfiss, Tensift & Morocco & MK733472 \\
\hline BIV2510 & Unio foucauldianus & Oumnass & Nfiss, Tensift & Morocco & MK733473 \\
\hline BIV2511 & Unio foucauldianus & Oumnass & Nfiss, Tensift & Morocco & MK733474 \\
\hline BIV2512 & Unio foucauldianus & Oumnass & Nfiss, Tensift & Morocco & MK733475 \\
\hline BIV2513 & Unio foucauldianus & Oumnass & Nfiss, Tensift & Morocco & MK733476 \\
\hline BIV2514 & Unio foucauldianus & Oumnass & Nfiss, Tensift & Morocco & MK733477 \\
\hline BIV2614 & Unio foucauldianus & Douar Ellil & Moulouya & Morocco & MK733478 \\
\hline BIV2615 & Unio foucauldianus & Douar Ellil & Moulouya & Morocco & MK733479 \\
\hline BIV2616 & Unio foucauldianus & Douar Ellil & Moulouya & Morocco & MK733480 \\
\hline BIV2617 & Unio foucauldianus & Douar Ellil & Moulouya & Morocco & MK733481 \\
\hline BIV2618 & Unio foucauldianus & Douar Ellil & Moulouya & Morocco & MK733482 \\
\hline BIV2619 & Unio foucauldianus & Douar Ellil & Moulouya & Morocco & MK733483 \\
\hline BIV3174 & Unio foucauldianus & Tetouan & Hajera, Martil & Morocco & MK733484 \\
\hline BIV3175 & Unio foucauldianus & Tetouan & Hajera, Martil & Morocco & MK733485 \\
\hline BIV3176 & Unio foucauldianus & Tetouan & Hajera, Martil & Morocco & MK733486 \\
\hline BIV 3177 & Unio foucauldianus & Tetouan & Hajera, Martil & Morocco & MK733487 \\
\hline BIV3178 & Unio foucauldianus & Tetouan & Hajera, Martil & Morocco & MK733488 \\
\hline BIV3179 & Unio foucauldianus & Tetouan & Hajera, Martil & Morocco & MK733489 \\
\hline BIV3214 & Unio foucauldianus & Zewiherate Taoughilt & Ouergha, Sebou & Morocco & MK733490 \\
\hline BIV3215 & Unio foucauldianus & Zewiherate Taoughilt & Ouergha, Sebou & Morocco & MK733491 \\
\hline BIV3216 & Unio foucauldianus & Zewiherate Taoughilt & Ouergha, Sebou & Morocco & MK733492 \\
\hline BIV3217 & Unio foucauldianus & Zewiherate Taoughilt & Ouergha, Sebou & Morocco & MK733493 \\
\hline
\end{tabular}


Table 1 (continued)

\begin{tabular}{|c|c|c|c|c|c|}
\hline Code & Species & Population & River Basin & Country & GenBank \\
\hline BIV3218 & Unio foucauldianus & Zewiherate Taoughilt & Ouergha, Sebou & Morocco & MK733494 \\
\hline BIV3219 & Unio foucauldianus & Zewiherate Taoughilt & Ouergha, Sebou & Morocco & MK733495 \\
\hline BIV2557 & Unio foucauldianus & Dar Bel Amri & Beth, Sebou & Morocco & MK733496 \\
\hline BIV2558 & Unio foucauldianus & Dar Bel Amri & Beth, Sebou & Morocco & MK733497 \\
\hline BIV2565 & Unio foucauldianus & Dar Bel Amri & Beth, Sebou & Morocco & MK733498 \\
\hline BIV2566 & Unio foucauldianus & Dar Bel Amri & Beth, Sebou & Morocco & MK733499 \\
\hline BIV2562 & Unio foucauldianus & Dar Bel Amri & Beth, Sebou & Morocco & MK733500 \\
\hline BIV 2577 & Unio foucauldianus & Dar Bel Amri & Beth, Sebou & Morocco & MK733501 \\
\hline BIV 2578 & Unio foucauldianus & Dar Bel Amri & Beth, Sebou & Morocco & MK733502 \\
\hline BIV 2579 & Unio foucauldianus & Dar Bel Amri & Beth, Sebou & Morocco & MK733503 \\
\hline BIV 4864 & Unio foucauldianus & Amghasse & Oued Tigrigra, Beth, Sebou & Morocco & MK733504 \\
\hline BIV 4865 & Unio foucauldianus & Amghasse & Oued Tigrigra, Beth, Sebou & Morocco & MK733505 \\
\hline BIV 4866 & Unio foucauldianus & Amghasse & Oued Tigrigra, Beth, Sebou & Morocco & MK733506 \\
\hline BIV 4867 & Unio foucauldianus & Amghasse & Oued Tigrigra, Beth, Sebou & Morocco & MK733507 \\
\hline BIV 4868 & Unio foucauldianus & Amghasse & Oued Tigrigra, Beth, Sebou & Morocco & MK733508 \\
\hline BIV 4869 & Unio foucauldianus & Amghasse & Oued Tigrigra, Beth, Sebou & Morocco & MK733509 \\
\hline BIV 2599 & Unio foucauldianus & Larache & Unnamed tributary, Loukos & Morocco & MK733510 \\
\hline BIV 2598 & Unio foucauldianus & Larache & Unnamed tributary, Loukos & Morocco & MK733511 \\
\hline BIV2600 & Unio foucauldianus & Larache & Unnamed tributary, Loukos & Morocco & MK733512 \\
\hline BIV2605 & Unio foucauldianus & Larache & Unnamed tributary, Loukos & Morocco & MK733513 \\
\hline BIV2606 & Unio foucauldianus & Larache & Unnamed tributary, Loukos & Morocco & MK733514 \\
\hline BIV2603 & Unio foucauldianus & Larache & Unnamed tributary, Loukos & Morocco & MK733515 \\
\hline BIV3236 & Unio foucauldianus & Aghbal & Bouregreg & Morocco & MK733516 \\
\hline BIV3238 & Unio foucauldianus & Aghbal & Bouregreg & Morocco & MK733517 \\
\hline BIV3239 & Unio foucauldianus & Aghbal & Bouregreg & Morocco & MK733518 \\
\hline BIV3240 & Unio foucauldianus & Aghbal & Bouregreg & Morocco & MK733519 \\
\hline BIV3241 & Unio foucauldianus & Aghbal & Bouregreg & Morocco & MK733520 \\
\hline BIV3257 & Unio foucauldianus & Aghbal & Grou, Bouregreg & Morocco & MK733521 \\
\hline BIV3258 & Unio foucauldianus & Aghbal & Grou, Bouregreg & Morocco & MK733522 \\
\hline BIV3259 & Unio foucauldianus & Aghbal & Grou, Bouregreg & Morocco & MK733523 \\
\hline BIV3260 & Unio foucauldianus & Aghbal & Grou, Bouregreg & Morocco & MK733524 \\
\hline BIV3261 & Unio foucauldianus & Aghbal & Grou, Bouregreg & Morocco & MK733525 \\
\hline BIV 3262 & Unio foucauldianus & Aghbal & Grou, Bouregreg & Morocco & MK733526 \\
\hline BIV 5106 & Unio foucauldianus & Rabat-Salé-Kénitra & Grou, Bouregreg & Morocco & MK733527 \\
\hline BIV 5107 & Unio foucauldianus & Rabat-Salé-Kénitra & Grou, Bouregreg & Morocco & MK733528 \\
\hline BIV5076 & Unio foucauldianus & Mohammedia & Nefifikh & Morocco & MK733529 \\
\hline BIV5077 & Unio foucauldianus & Mohammedia & Nefifikh & Morocco & MK733530 \\
\hline BIV5078 & Unio foucauldianus & Mohammedia & Nefifikh & Morocco & MK733531 \\
\hline BIV5081 & Unio foucauldianus & Mohammedia & Nefifikh & Morocco & MK733532 \\
\hline BIV5082 & Unio foucauldianus & Mohammedia & Nefifikh & Morocco & MK733533 \\
\hline BIV5083 & Unio foucauldianus & Mohammedia & Nefifikh & Morocco & MK733534 \\
\hline BIV3237 & Unio gibbus & Aghbal & Bouregreg & Morocco & MK733535 \\
\hline BIV3250 & Unio gibbus & Aghbal & Bouregreg & Morocco & MK733536 \\
\hline BIV3252 & Unio gibbus & Aghbal & Bouregreg & Morocco & MK733537 \\
\hline BIV3253 & Unio gibbus & Aghbal & Bouregreg & Morocco & MK733538 \\
\hline BIV725 & Unio gibbus & Guelmim & Noun & Morocco & MK733539 \\
\hline BIV727 & Unio gibbus & Guelmim & Noun & Morocco & MK733540 \\
\hline BIV728 & Unio gibbus & Guelmim & Noun & Morocco & MK733541 \\
\hline BIV729 & Unio gibbus & Guelmim & Noun & Morocco & MK733542 \\
\hline BIV730 & Unio gibbus & Guelmim & Noun & Morocco & MK733543 \\
\hline BIV811 & Unio gibbus & Sidi Said Maachou & Oum Er-Rbia & Morocco & MK733544 \\
\hline BIV821 & Unio gibbus & Sidi Said Maachou & Oum Er-Rbia & Morocco & MK733545 \\
\hline UG4 & Unio gibbus & Dar Bel Amri & Beth, Sebou & Morocco & MK733546 \\
\hline UG5 & Unio gibbus & Dar Bel Amri & Beth, Sebou & Morocco & MK733547 \\
\hline UG6 & Unio gibbus & Dar Bel Amri & Beth, Sebou & Morocco & MK733548 \\
\hline BIV2537 & Unio gibbus & Dar Bel Amri & Beth, Sebou & Morocco & MK733549 \\
\hline UG11 & Unio gibbus & Kenitra & Mda & Morocco & MK733550 \\
\hline UG16 & Unio gibbus & Kenitra & Mda & Morocco & MK733551 \\
\hline UG13 & Unio gibbus & Kenitra & Mda & Morocco & MK733552 \\
\hline UG14 & Unio gibbus & Kenitra & Mda & Morocco & MK733553 \\
\hline UG15 & Unio gibbus & Kenitra & Mda & Morocco & MK733554 \\
\hline PL392 & Unio gibbus & Unkonwn & Barbate & Spain & MK733555 \\
\hline BIV5079 & Unio gibbus & Mohammedia & Nefifikh & Morocco & MK733556 \\
\hline BIV5080 & Unio gibbus & Mohammedia & Nefifikh & Morocco & MK733557 \\
\hline BIV5085 & Unio gibbus & Mohammedia & Nefifikh & Morocco & MK733558 \\
\hline BIV5086 & Unio gibbus & Mohammedia & Nefifikh & Morocco & MK733559 \\
\hline BIV5087 & Unio gibbus & Mohammedia & Nefifikh & Morocco & MK733560 \\
\hline BIV5088 & Unio gibbus & Mohammedia & Nefifikh & Morocco & MK733561 \\
\hline BIV5089 & Unio gibbus & Mohammedia & Nefifikh & Morocco & MK733562 \\
\hline BIV5090 & Unio gibbus & Mohammedia & Nefifikh & Morocco & MK733563 \\
\hline BIV5092 & Unio gibbus & Mohammedia & Nefifikh & Morocco & MK733564 \\
\hline BIV5095 & Unio gibbus & Mohammedia & Nefifikh & Morocco & MK733565 \\
\hline BIV5096 & Unio gibbus & Mohammedia & Nefifikh & Morocco & MK733566 \\
\hline BIV5097 & Unio gibbus & Mohammedia & Nefifikh & Morocco & MK733567 \\
\hline BIV5098 & Unio gibbus & Mohammedia & Nefifikh & Morocco & MK733568 \\
\hline
\end{tabular}


Table 1 (continued)

\begin{tabular}{|c|c|c|c|c|c|}
\hline Code & Species & Population & River Basin & Country & GenBank \\
\hline BIV5099 & Unio gibbus & Mohammedia & Nefifikh & Morocco & MK733569 \\
\hline BIV5100 & Unio gibbus & Mohammedia & Nefifikh & Morocco & MK733570 \\
\hline BIV5101 & Unio gibbus & Mohammedia & Nefifikh & Morocco & MK733571 \\
\hline BIV5102 & Unio gibbus & Mohammedia & Nefifikh & Morocco & MK733572 \\
\hline BIV5104 & Unio gibbus & Mohammedia & Nefifikh & Morocco & MK733573 \\
\hline BIV5105 & Unio gibbus & Mohammedia & Nefifikh & Morocco & MK733574 \\
\hline
\end{tabular}

foucauldianus and 40 U. gibbus).

\subsection{Permanent freshwater sections and distribution maps}

In order to map intermittent river segments, Hydrosheds (Lehner et al., 2008) river network was used as a base, removing the sections subjected to any period of desiccation during the last 15 years. Temporary dry sections were identified using Google Earth satellite imagery from 2003 to 2017. The whole Moroccan hydrographic network was visually checked for water absence in each image for all years available. When at least one image of river section revealed a clear absence of water, that section was identified as intermittent and removed from the Hydrosheds layer. Images where there was no clear view of the water level, e.g., due to tree or rock cover, shadow or low resolution were not removed and therefore may lead to an over-estimation of permanent water surface. However, error should be low given the generally high image quality, and the fact that Google Earth satellite imagery from different years and/or months was available throughout Morocco, which allowed for a standardized identification of intermittent sections.

Potential areas of occurrence, for each basin and each species included river sections between recent confirmed presence sites. Since the presence of empty shells does not provide any indication on how far upstream a population extends, shells (i.e. dead animals) were considered as presences when upstream of sites with living individuals; or in rivers where only shells were found. Maps of potential distribution for each species were obtained by overlapping presence and putative presence points with the Hydrobasin level 8 polygons (Lehner and Grill, 2013). A species richness map was then produced by overlapping species maps.

\subsection{DNA extraction, amplification and sequencing}

Total DNA was extracted using a high-salt protocol (Sambrook et al., 1989). The F-type COI mtDNA (Ca. $700 \mathrm{bp}$ fragment) was amplified with LCO_22me and HCO_700dy primers (Walker et al., 2007), using PCR conditions described in Froufe et al. (2014) with the annealing temperatures varying from $48{ }^{\circ} \mathrm{C}$ to $55^{\circ} \mathrm{C}$. Sequences were obtained using the BigDye sequencing protocol (Applied Biosystems 3730xl) by Macrogen Inc., Korea, using the same primers.

\subsection{Phylogenetic and Phylogeographic analyses}

Forward and reverse Chromatograms were analysed and edited using ChromasPro 2.6.2 (Technelysium, Tewantin, Australia). The new sequences were deposited in GenBank (Table 1). For each species, an alignment was constructed using ClustalW, in Bioedit v7.2.5 (Hall, 1999), including the previously published sequences from Morocco, and/or from other relevant geographical areas outside Morocco, e.g. sequenced U. gibbus from Spain (Araujo et al., 2009, 2010, 2016; Khalloufi et al., 2011; Froufe et al., 2014, 2016b, 2017; Froufe et al., 2016a; Klishko et al., 2018; Sousa et al., 2018 and references within).

For the Anodonta sp., given the many uncertainties that still exist about which species is present in Morocco, a phylogenetic analysis was conducted, including all the Anodonta sp. from the present study, the four main mtDNA clades of Anodonta anatina previously described
(Froufe et al., 2014, 2017; Klishko et al., 2018), and all available sequences for Anodonta cygnea and Anodonta exulcerata (Porro, 1838). Cristaria plicata (Leach, 1814) (GenBank: EU698940), Anemina arcaeformis (Heude, 1877) (GenBank: NC_026674), Sinanodonta woodiana (Lea, 1834) (GenBank: HQ283346) were used as outgroups. The most appropriate model of molecular substitution for each codon position was selected using jModeltest 2 (Darriba et al., 2012). The best scoring models using Akaike Information Criterion were GTR + I for the first COI codon position, F81 for the second, and GTR for the third. Phylogenetic relationships were estimated by Bayesian inference using MrBayes v. 3.2.6 (Ronquist et al., 2012) in the HPC Black Box of the San Diego Supercomputer Center through the CIPRES S1cience Gateway (https://www.phylo.org). Two independent runs of $2.5 \times 10^{7}$ generations were sampled at intervals of 1000 generations producing a total of 25,000 trees. The burn-in value was determined upon convergence of log likelihood and parameter values, using Tracer v1.7 (Rambaut et al., 2018).

The relationships among closely related haplotypes within each species were evaluated by the construction of a maximum parsimony network under a 95\% criterion using TCS 1.2.1 (Clement et al., 2000) and plotted using tcsBU (Múrias Dos Santos et al., 2015). The uncorrected $p$-distances were calculated using MEGA 7.0 (Kumar et al., 2016) and the nucleotide diversity measures were calculated using DnaSP v5.10.01 (Rozas and Rozas, 1995). In order to test for the molecular demographic signature of a hypothesized Pleistocene range expansion, Fu's Fs (1997) and Tajima's D (1989) statistics were calculated using ARLEQUIN v3.5.2.2 (Excoffier and Lischer, 2010).

\subsection{Conservation status assessment}

$\mathrm{AOO}$ and $\mathrm{EOO}$ were calculated using two river networks (total and permanent-only), and five area strategies: a) $2 \mathrm{~km}$ grid overlay, b) $1 \mathrm{~km}$ grid overlay, c) $2 \mathrm{~km}$ and d) $1 \mathrm{~km}$ buffer along river length, and e) mean river width $\times$ length. Mean river width was obtained per basin as the average of six equidistant points within a species' potential range. AOO comprised only confirmed presence points with a $300 \mathrm{~m}$ buffer along the river length, while EOO included also the potential segments. EOO and $\mathrm{AOO}$ values were then used to assess the Red List species conservation status of each species in Morocco (see Appendix A for the full accounts).

\section{Results}

\subsection{Permanent freshwater sections and distribution maps}

Intermittent rivers are more prevalent in the southern regions of Morocco, with most permanent streams being located north of the Atlas Mountains (Fig. 1; Shapefile as Appendix B). Notably, permanent segments can still be found in the relict endorheic basins of Ziz and Ghir. Total permanent river length was estimated at $14,892 \mathrm{~km}, 18.3 \%$ of the total river network.

Sites with extant populations are more numerous in the North of Morocco for all species, with $P$. littoralis, $U$. foucauldianus and $U$. gibbus being distributed throughout the country, while $A$. anatina and $P$. marocanus seem to be restricted to only a few localities (Figs. 2-6). 

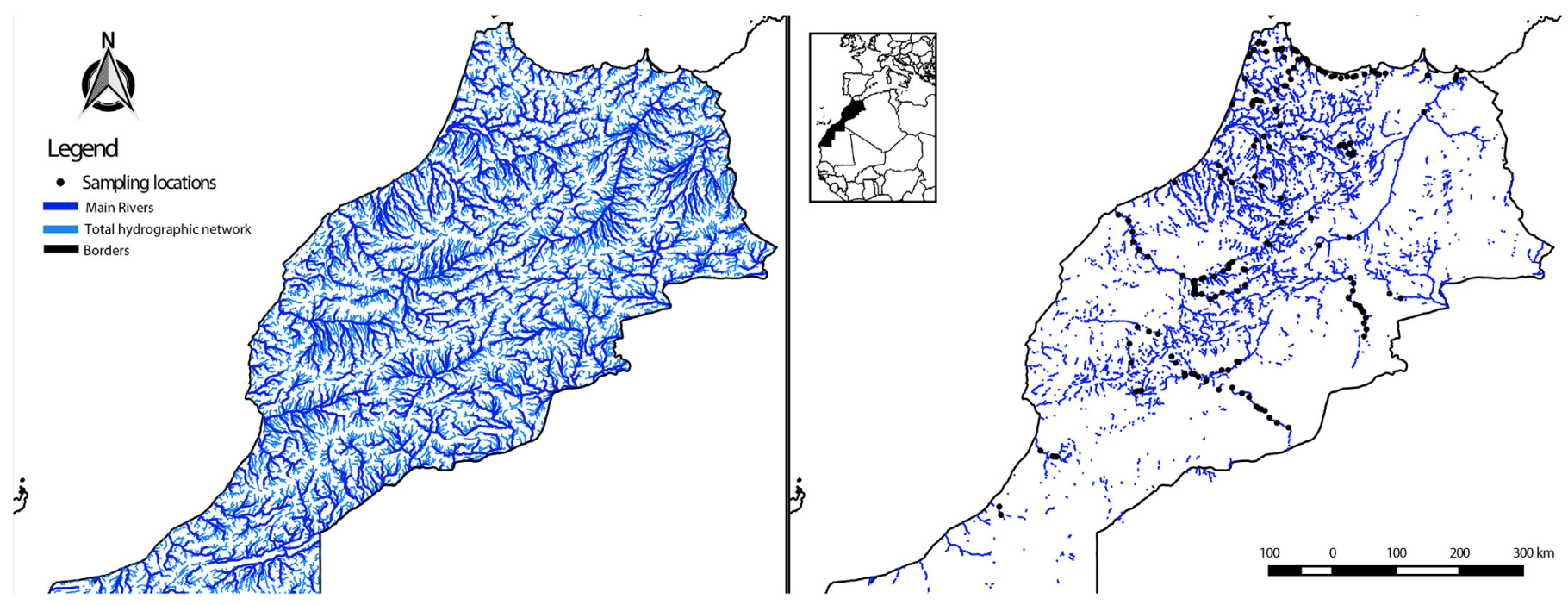

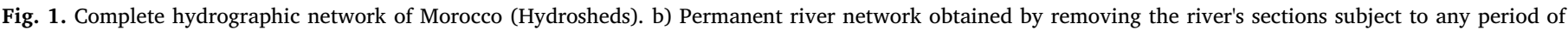
desiccation during the last 15 years, with sampling locations superimposed.

Based on shell occurrence, unsampled populations may be present for: A. anatina in Oum Er Rbia and Mda basins (Fig. 2); P. littoralis in Mda, Loukos, Sebou and Oum Er Rbia basins (Fig. 3); U. foucauldianus in Mda, Loukos and Oum Er Rbia basins (Fig. 4) and P. marocanus in the lower Moulouya basin (Fig. 6).

The northern regions of the country support the highest species richness (Fig. 7). Oum Er Rbia is the unique basin containing all five freshwater mussel species, although there is no level-8 basin with more than four species. The highest species count is located in Mda (Fig. 7). Species richness per basin is lower in southern regions, with only Noun and Massa supporting more than one species.

\subsection{Phylogeny of Anodonta and phylogeographic structure of freshwater} mussels in Morocco

All mtDNA sequences obtained were considered F-Type given that no sequence similar to M-Type was detected. No insertions, deletions or stop codons were observed after translating all sequences to amino acids.
From the preliminary analyses on the Anodonta specimens, the present results show that the Moroccan sequences cluster within the current concept of $A$. anatina. The three previously identified mtDNA clades within A. anatina (Froufe et al., 2014) were replicated in this new phylogeny: a first clade including all the individuals from Iberia (except those from the Ebro basin) and the single Moroccan haplotype; a second clade including all the European non-Iberian and non-Italian individuals; and a third clade including all the individuals from Italy and from the Ebro basin. All except the third clade show high support (Fig. 8). Therefore, based on the low genetic divergence (see below), we hereafter consider all Anodonta Moroccan specimens as A. anatina.

The $A$. anatina dataset included 191 sequences, and the alignment was 555 nucleotides (nt) long. All the 12 Moroccan individuals sampled (6 from each basin), shared the same haplotype corresponding to a newly described haplogroup, closely related to the Iberian haplogroups (Fig. 2). The uncorrected $p$-distances between all haplogroups ranged between $0.96 \%$ and $3.28 \%$ (Table 2 ).

The $P$. littoralis dataset included 114 sequences and the alignment was $607 \mathrm{nt}$ long. The most frequent haplotype was present in 31

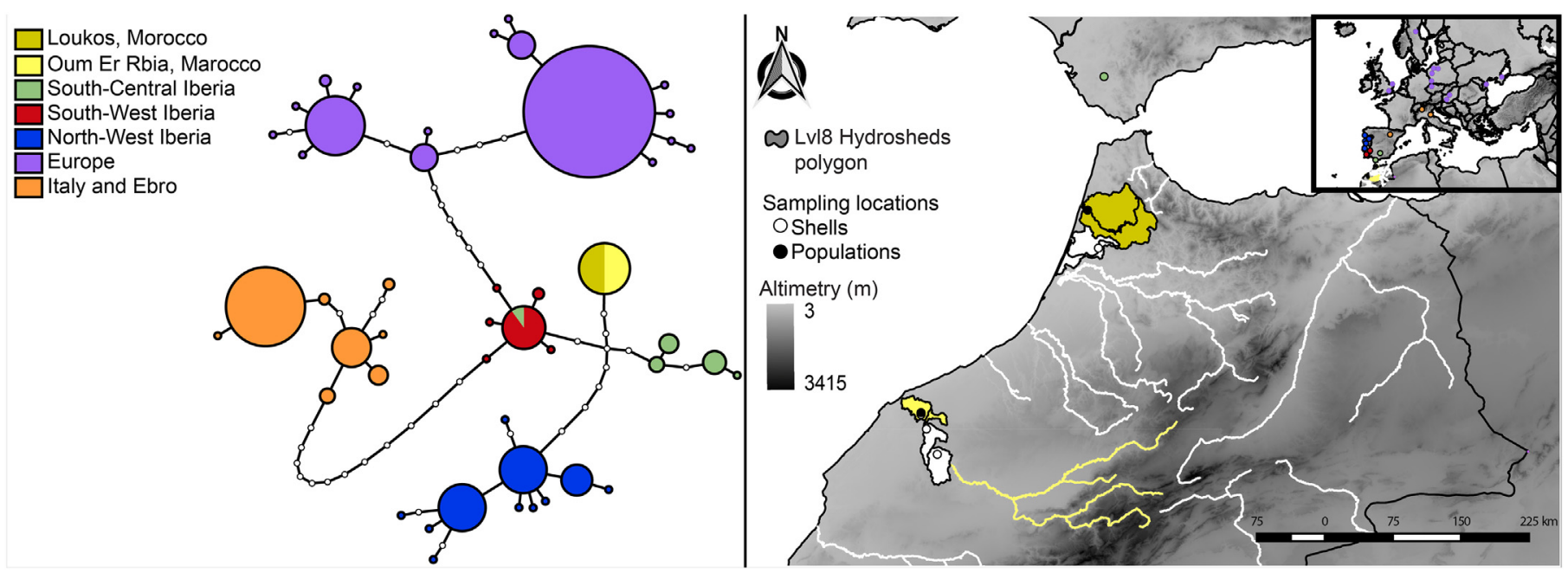

Fig. 2. a) COI haplotype (TCS) network showing the relationships of $A$. anatina haplotypes. Circle size is proportional to the observed haplotype frequencies and white points represent unobserved haplotypes and potential intermediates. Colours correspond to the geographic distribution as seen in b). b) Map showing the distribution of $A$. anatina, black dots represent the recently sampled individuals, white dots represent sampled shells. Lvl8 hydrosheds polygon layer shows the estimated distribution of the species, where white colour represents the potential distribution and other colours represent effective distribution sites. These colours correspond to the haplotypes represented in the network. The colours of the rivers are according the colours represented in the haplotype network as well. 

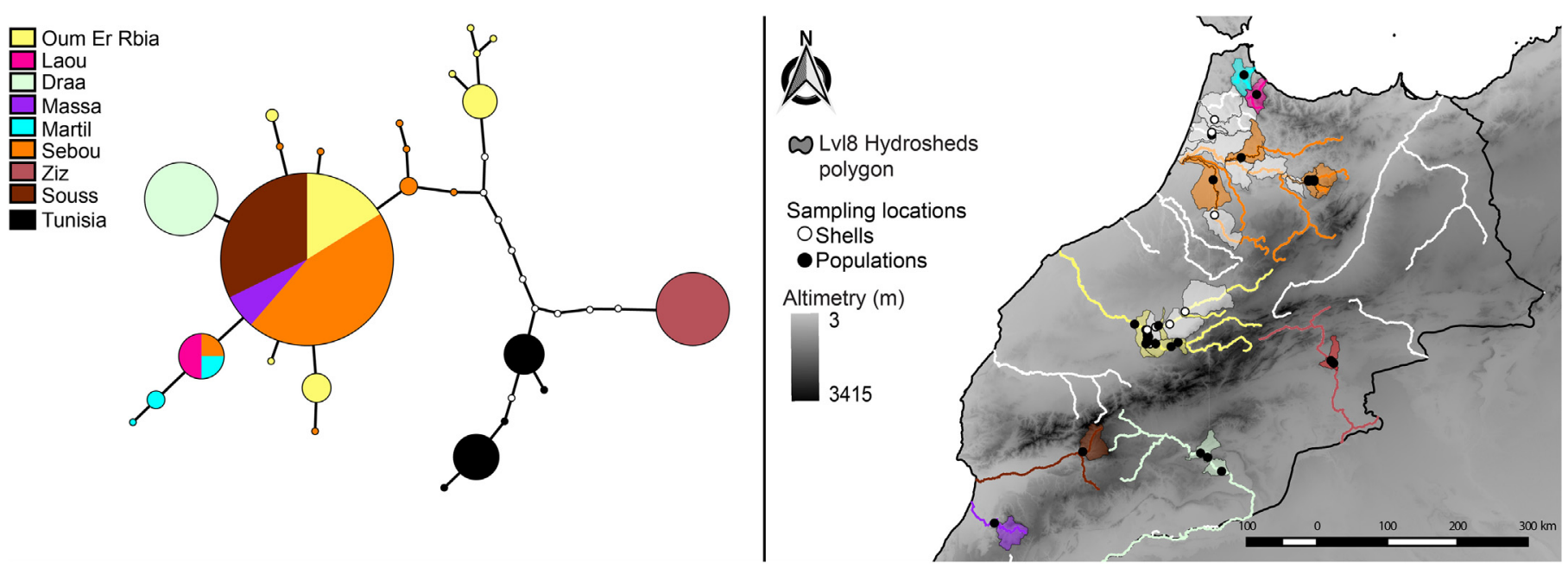

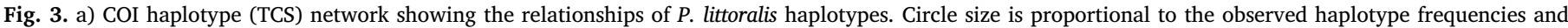

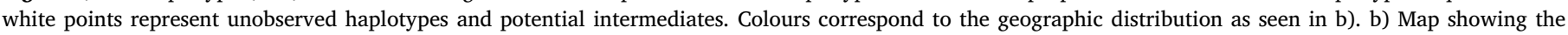

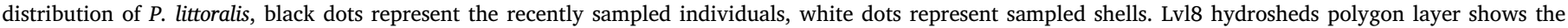

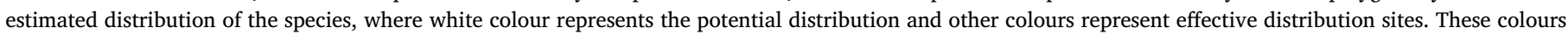
correspond to the haplotypes represented in the network. The colours of the rivers are according the colours represented in the haplotype network as well.

individuals and widely distributed. Oum Er Rbia and Sebou basins contained 11 out of 15 total singletons (Fig. 3). The highest values of haplotype diversity were observed in P. littoralis, $\mathrm{Hd}=0.887$ (Table 3). Three haplogroups were retrieved: the first including all individuals from Ziz River (Fig. 3); the second containing all the remaining Moroccan individuals; and the third including only Tunisian individuals. The uncorrected $p$-distances varied from $1.11 \%$ to $1.54 \%$ (Table 2) and signs of recent population expansion were found in Sebou basin (D = - 1.65639, $p<0.05$; Table 3).

The $U$. foucauldianus dataset included 121 sequences and the alignment was $624 \mathrm{nt}$ long. Most individuals $(N=78)$ shared the same haplotype (Fig. 4), and the tests of recent population expansion were significant for the species $(\mathrm{D}=-1.56240, p<0.05$; Fs $=-9.13433$, $p<0.02$ ) (Table 3).

The $U$. gibbus dataset included 65 sequences and the alignment was $559 \mathrm{nt}$ long. Out of the 12 haplotypes, nine were from Morocco, four from Tunisia and one from Spain (Fig. 5). One side of the network is formed by one haplotype present in four Moroccan populations, only one mutation from the Spanish haplotype; the other side is formed by the four Tunisian haplotypes (Fig. 5). The uncorrected $p$-distances varied from $0 \%$ to $2.25 \%$ for $U$. gibbus (Table 2 ).

The $P$. marocanus dataset included 22 sequences and the alignment was $657 \mathrm{nt}$ long. The haplotype diversity within Oum Er Rbia basin $(\mathrm{Hd}=0.711)$ was higher than in Sebou basin $(\mathrm{Hd}=0.303)$ (Table 3$)$ and the haplotype network is shown in Fig. 6. Demographic history tests were not significant, showing no evidence for recent expansion (Table 3).

\subsection{Conservation status}

EOO and AOO varied considerably across measurement strategies, with the $2 \times 2 \mathrm{~km}$ grid having 32 to 583 times larger values than the mean river width strategy (Table 4, Fig. 8). The latter strategy resulted in all species being considered as CR according to criterion B, whereas
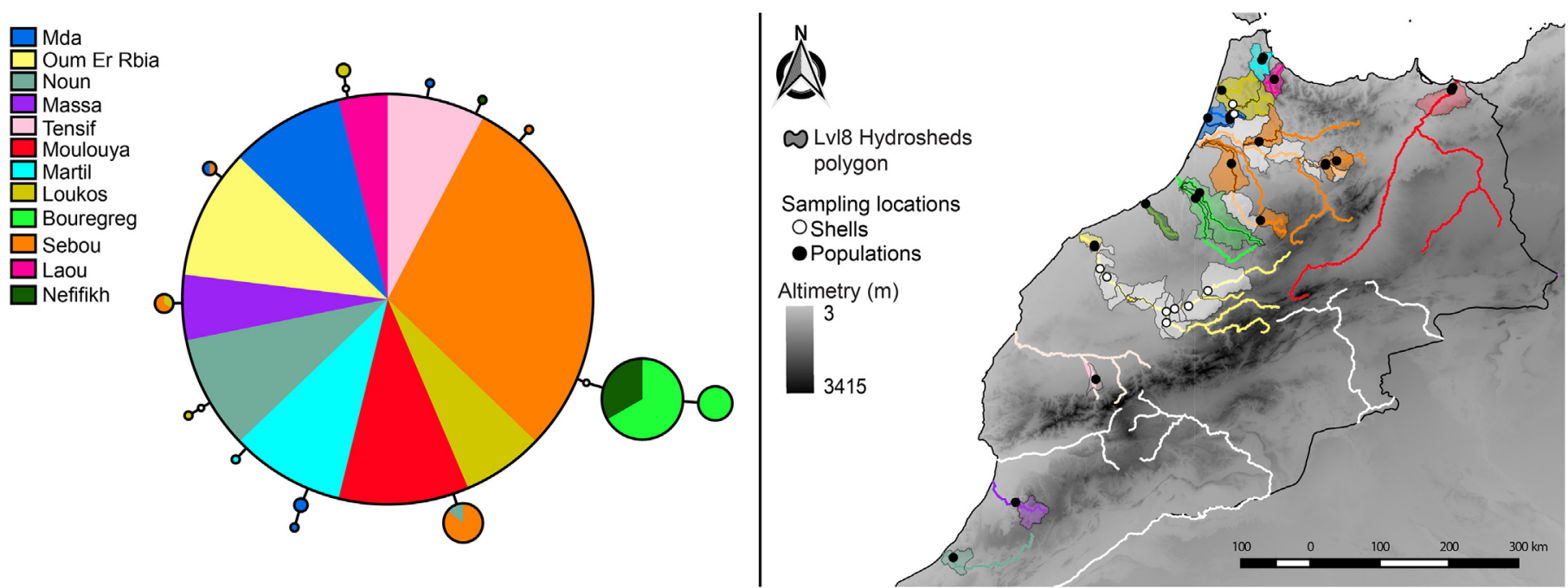

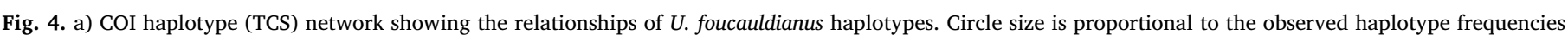

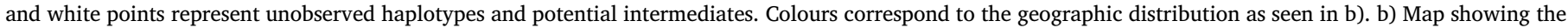

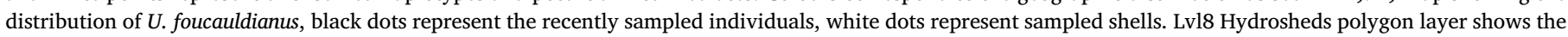

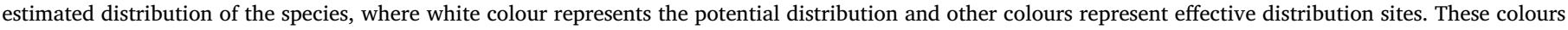
correspond to the haplotypes represented in the network. The colours of the rivers are according the colours represented in the haplotype network as well. 


\begin{tabular}{l}
$\square$ Sebou \\
\hline Bouregreg \\
Noun \\
$\square$ Oum Er Rbia \\
Mda \\
Spain, Barbate \\
Nefifikh \\
Tunisia
\end{tabular}

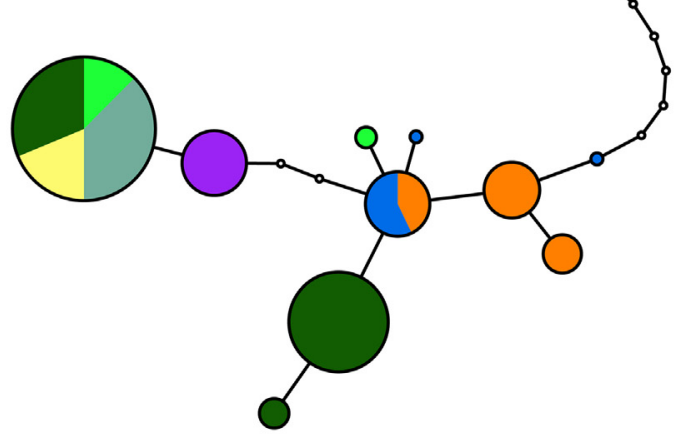

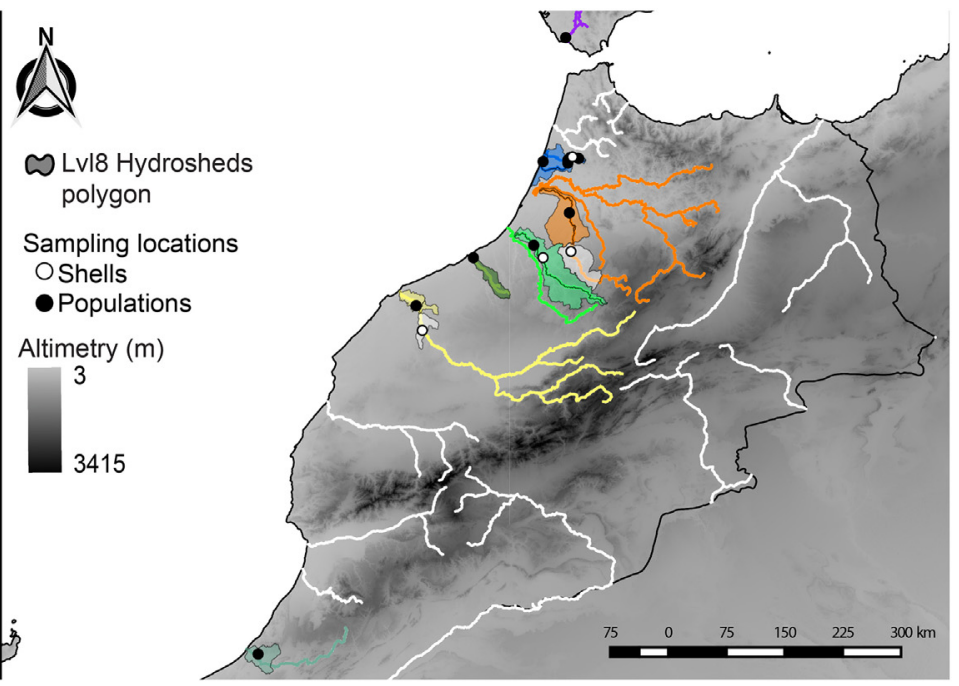

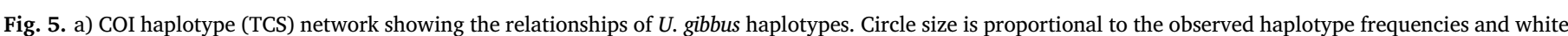

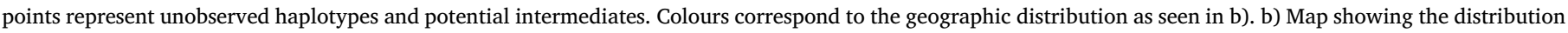

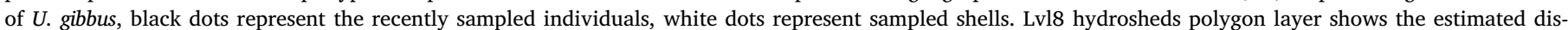

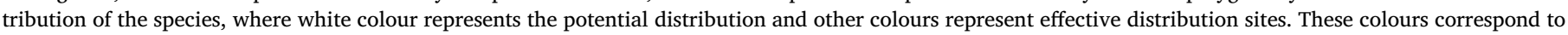
the haplotypes represented in the network. The colours of the rivers are according the colours represented in the haplotype network as well.

the $2 \mathrm{~km}$ grid/buffer returns a mix of EN or CR. Considering just the permanent river network resulted in estimated EOO decreases of up to $13 \%$, but without influence in conservation statuses. Following these results, all complete conservation status accounts are presented in Appendix A and were assessed using the mean river width strategy for the estimation of $\mathrm{AOO}$ and $\mathrm{EOO}$.

\section{Discussion}

This study represents the first all-inclusive genetic diversity and distribution assessment of all species of freshwater mussels in Morocco, providing the basis for future conservation management actions and further research. The comparison of AOO and EOO calculation methods contributes towards a more accurate way of determining the conservation status of sessile and permanent refugial freshwater taxa. Additionally, the mapping of river intermittency here performed will be highly valuable for future studies and allow better management policies for freshwater taxa conservation in this semi-arid region. This study has shed light on the long lasting taxonomic uncertainties concerning Anodonta sp., and increased the phylogeographic knowledge on the five native species, A. anatina, $P$. marocanus, $P$. littoralis, $U$. foucauldianus and $U$. gibbus present in Morocco.

\subsection{Phylogeographic structure of the freshwater mussels of Morocco}

The north-south gradient of genetic diversity, species richness and distribution range size is strongly coherent with water availability and river intermittence. Whereas north of High and Middle Atlas Mountains

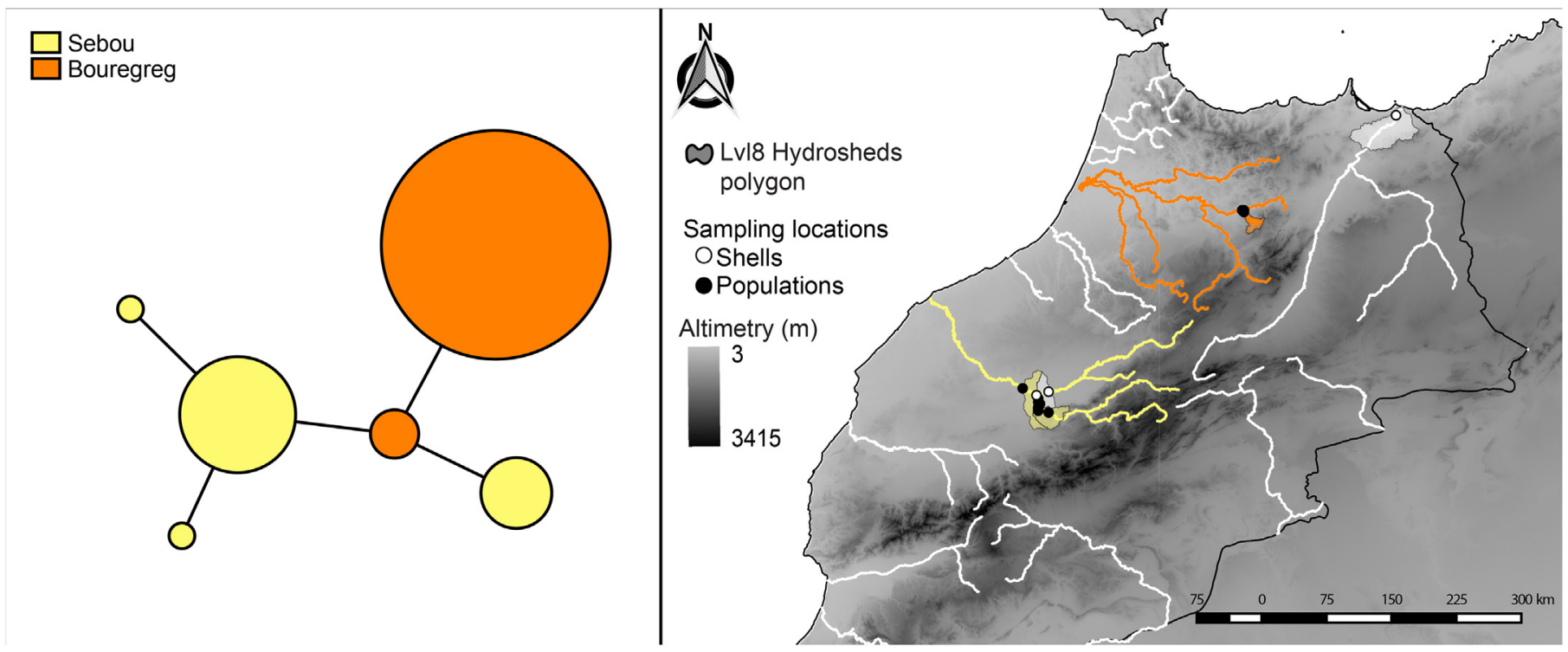

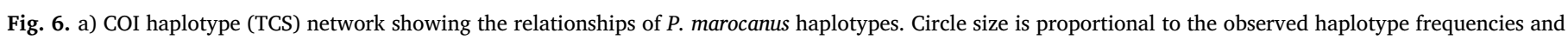

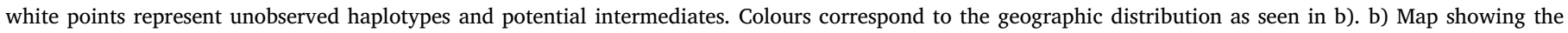

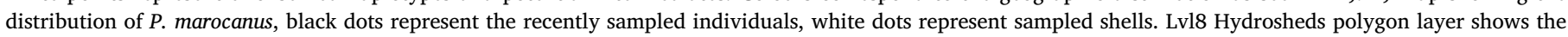

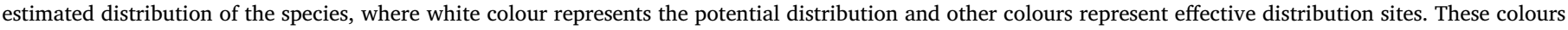
correspond to the haplotypes represented in the network. The colours of the rivers are according the colours represented in the haplotype network as well. 


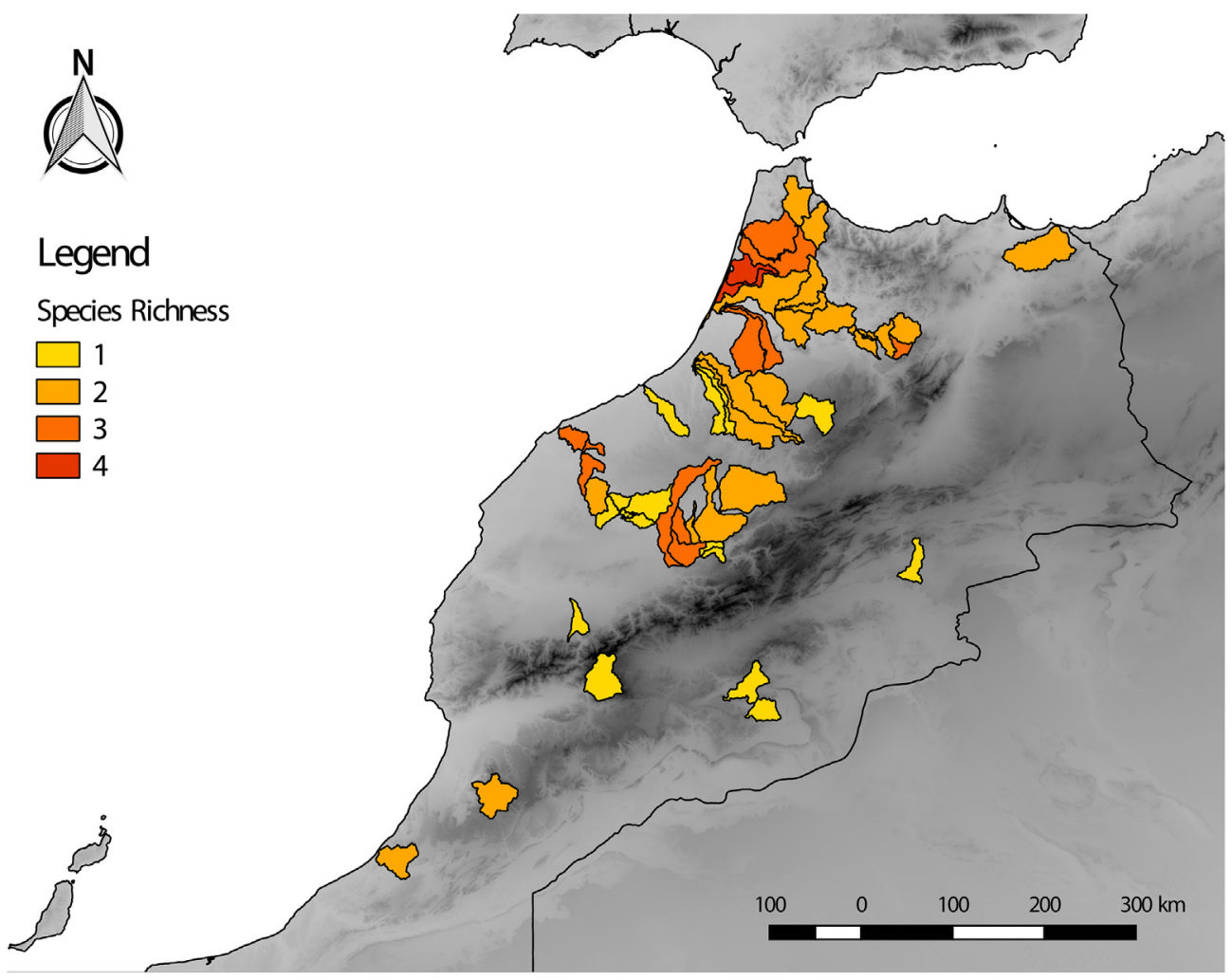

Fig. 7. Map of species richness representing the overlapping potential areas of distribution. Colours differ according to the number of species present in each area.

many rivers are permanent, in southern regions mussel populations are usually restricted to small pools subjected to very harsh abiotic conditions (e.g. oxygen, conductivity, $\mathrm{pH}$ and temperature; Sheldon and Fellows, 2010; Sheldon et al., 2010). During extreme drought conditions, most of the southern rivers in Morocco probably dry out, causing local extirpations. The consequently more pronounced genetic drift results in lower intraspecific genetic diversity. Similar patterns are found in other taxa, and have been attributed to the onset of the Sahara Desert and climatic shifts between humid and arid phases during the Plio-Pleistocene (Le Houérou, 1992). Although humid periods allow demographic expansions and recolonization of more arid (southern) regions, only the more resilient and adaptable species can do so and persist there (Brito et al., 2014). Even after the last Glacial Maximum $(\sim 18,000$ years) the fluctuation continued, sometimes changing every 100 years (Sarnthein, 1978; Schuster et al., 2006).

Another prevalent pattern was the phylogeographic separation between Tunisian and Moroccan haplotypes (observed in P. littoralis and $U$. gibbus). This has been found not only in freshwater mussels (Khalloufi et al., 2011; Araujo et al., 2016; Froufe et al., 2016b) but also in other animals (e.g. fishes, Machordom and Doadrio, 2001; amphibians and reptiles, Recuero et al., 2007; Beddek et al., 2018), but like in many other taxa, sampling gaps in Algeria preclude further conclusions.

\subsubsection{Anodonta anatina}

Regarding Anodonta sp., many uncertainties persisted about which species exist in Morocco and the only recent records of its presence are from the Oum Er Rbia basin (Sousa et al., 2016). It has been speculated that Morocco either holds an endemic species named Anodonta pallaryi (Bédé, 1932) (Haas, 1969; Van Damme and Ghamizi, 2010a), or a wideranged European species, Anodonta anatina (Linnaeus, 1758) (Graf and Cummings, 2015). To date, no studies using molecular markers have been performed in order to support either classification. The present molecular data clusters the single Moroccan Anodonta haplotype within A. anatina, with a low genetic distance from the Southern Iberian haplogroups (Figs. 2 and 8 and Table 2). Additional nuclear data from a small number of individuals show that Iberian and Moroccan populations share the same haplotype for the Histone 3 (H3) and 28S ribosomal genes (data not shown). Therefore, we consider the previously nominal taxa Anodonta (Liouvillea) pallaryi Bédé, 1932, Anodonta (Liouvillea) theryi Bédé, 1932 and Anodonta (Liouvillea) gruveli Perès, 1938 as junior synonyms of Anodonta anatina (Linnaeus, 1758). Still, a thorough taxonomic revision should be performed in the future using nuclear molecular markers together with morphological and ecological traits. The grouping of the Moroccan haplotype with the Iberian haplogroups (Fig. 2), whose genetic structure resulted from a likely refugia within refugia process (i.e. several distinct refugia within Iberian Peninsula; Froufe et al., 2014, 2017), further highlighting Morocco as an additional refugium in this species' phylogeographic history (Husemann et al., 2014; Prendergast et al., 2016). The wide European distribution and the close genetic proximity of the Moroccan and Southern Iberian populations (Figs. 2 and 8 and Table 2), suggest an Iberian origin for the colonization of the Maghreb. Given that the Mediterranean Sea represents an effective barrier, colonization may have taken place over the land bridge that was formed around 5.6 Mya between Europe and Africa. Post-Messinian vicariance has already been associated with divergences between other species of freshwater mussels (Araujo et al., 2016; Bolotov et al., 2016; Froufe et al., 2016a, 2016b). However, in those cases, divergence between Maghrebian and Iberian populations was much higher (3.2\% for Unio spp. and 9.2\% for Margaritiferidae, compared to $1 \%$ ), which may imply faunal exchanges over previous land bridges (Bolotov et al., 2016), or even, in the case of $A$. anatina, a posterior event of dispersal.

\subsubsection{Potomida littoralis}

This species' high haplotypic diversity and wide distribution in Morocco (Fig. 3 and Table 3) indicates a higher adaptability to the environmental conditions found throughout Moroccan freshwater ecosystems. Further support comes from $P$. littoralis being the only freshwater mussel species found in the Draa and Ziz basins, both located in arid regions and being mostly intermittent along their extent (Clavero 


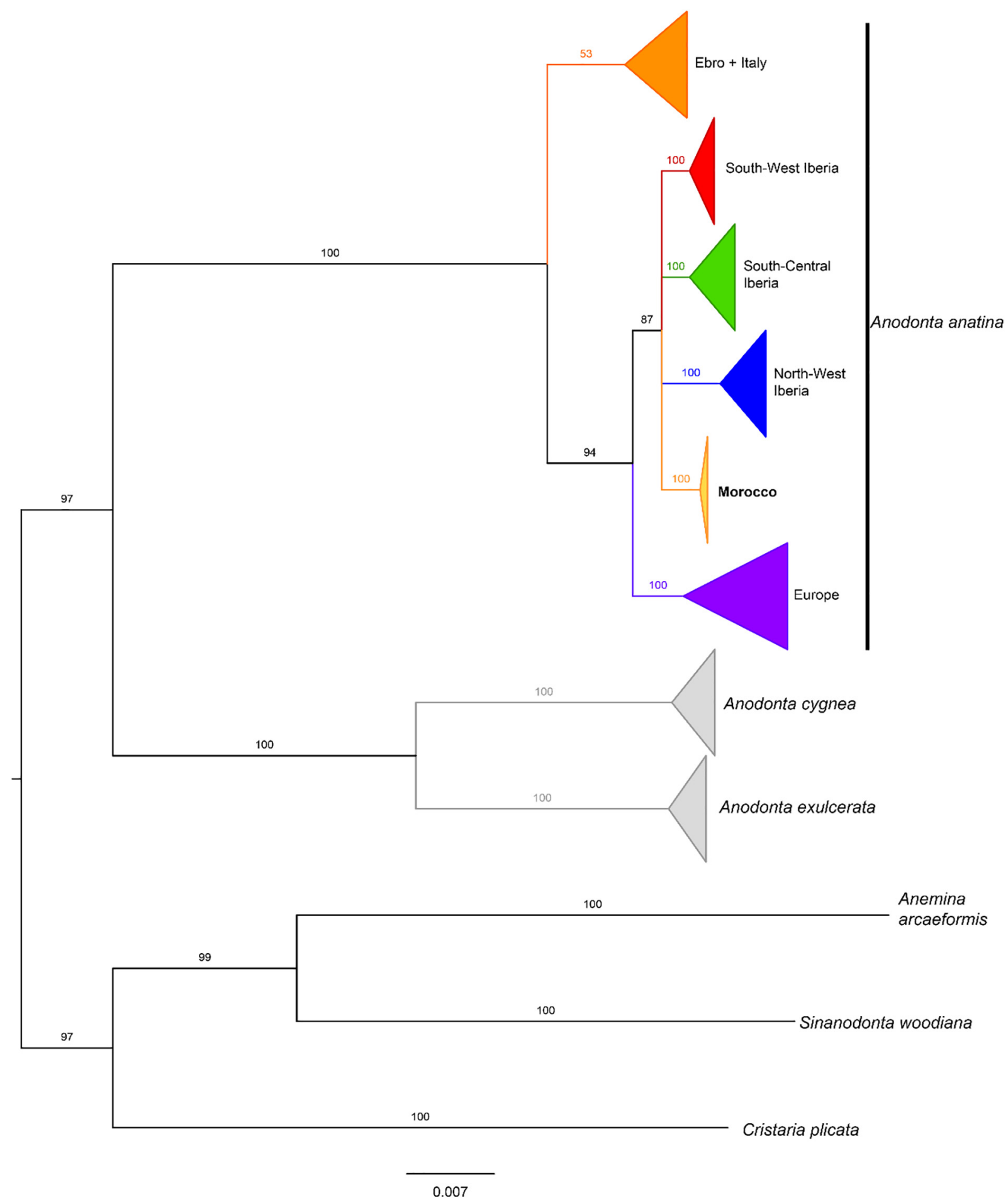

Fig. 8. Anodonta Bayesian phylogenetic tree of the COI fragment. Cristaria plicata, Anemina arcaeformis and Sinanodonta woodiana were used as outgroups. The values above the branches indicate posterior probabilities. Within A. anatina, colours highlight the major mtDNA groups corresponding to the geographic distribution as seen in Fig. 2.

et al., 2015, 2017). The haplotype from the endorheic Ziz basin is closer to Tunisian haplotypes than to Moroccan ones, suggesting gene-flow during past wet periods in the Sahara like during the mid-Holocene (Drake et al., 2011; Clavero et al., 2015).

Even though the demographic history tests were inconclusive, when excluding Ziz haplotype the Fu's Fs results are significant for a recent expansion. Although genetic distinctiveness among basins suggests the species persisted in several basins, Sebou and Oum Er Rbia basins possess the highest genetic diversity. This is probably due to a more stable environment during Plio-Pleistocene climatic fluctuations and more constant water flow from the mountains.

\subsubsection{Unio foucauldianus}

This study represents a great increase in the data available for $U$. foucauldianus (see Froufe et al., 2016a), expanding the known range to 12 basins. However, unlike $P$. littoralis, $U$. foucauldianus must have suffered a region-wide bottleneck, resulting in much lower genetic diversity $(\mathrm{Hd}=0.566$ - Table $3 ; 65 \%$ of the individuals sharing the same 
Table 2

Mean genetic divergences for the COI dataset, among the populations and/or haplogroups of Anodonta anatina, Potomida littoralis and Unio gibbus.

\begin{tabular}{|c|c|c|c|c|c|c|c|c|c|c|}
\hline Species & Populations/Haplogroups & 1 & 2 & 3 & 4 & 5 & 6 & 7 & 8 & 9 \\
\hline Anodonta anatina & 1 - European & & & & & & & & & \\
\hline Anodonta anatina & 2 - Italy/Ebro & 0.03282 & & & & & & & & \\
\hline Anodonta anatina & 3- South West Iberia & 0.02148 & 0.02852 & & & & & & & \\
\hline Anodonta anatina & 4 -South Central Iberia & 0.02253 & 0.03041 & 0.0096 & & & & & & \\
\hline Anodonta anatina & 5 - North West Iberia & 0.02623 & 0.03505 & 0.01491 & 0.01641 & & & & & \\
\hline Anodonta anatina & 6 - Morocco & 0.02282 & 0.02988 & 0.00973 & 0.0112 & 0.01602 & & & & \\
\hline Potomida littoralis & 1 - Martil & & & & & & & & & \\
\hline Potomida littoralis & 2 - Massa & 0.003 & & & & & & & & \\
\hline Potomida littoralis & 3 - Oum Er Rbia & 0.008 & 0.005 & & & & & & & \\
\hline Potomida littoralis & 4 - Sebou & 0.004 & 0.001 & 0.005 & & & & & & \\
\hline Potomida littoralis & 5 - Laou & 0.001 & 0.002 & 0.006 & 0.002 & & & & & \\
\hline Potomida littoralis & 6 - Draa & 0.005 & 0.002 & 0.006 & 0.003 & 0.003 & & & & \\
\hline Potomida littoralis & $7-\mathrm{Ziz}$ & 0.018 & 0.015 & 0.017 & 0.015 & 0.016 & 0.013 & & & \\
\hline Potomida littoralis & 8 - Souss & 0.003 & 0 & 0.005 & 0.001 & 0.002 & 0.002 & 0.015 & & \\
\hline Potomida littoralis & 9 - Tunisia & 0.017 & 0.014 & 0.016 & 0.015 & 0.016 & 0.013 & 0.011 & 0.014 & \\
\hline Potomida littoralis & 1 - Moroccan Haplogroup & & & & & & & & & \\
\hline Potomida littoralis & 2 - Ziz Haplogroup & 0.0154 & & & & & & & & \\
\hline Potomida littoralis & 3 - Tunisian Haplogroup & 0.0149 & 0.0111 & & & & & & & \\
\hline Unio gibbus & 1 - Bouregreg & & & & & & & & & \\
\hline Unio gibbus & 2 - Noun & 0.0045 & & & & & & & & \\
\hline Unio gibbus & 3 - Oum Er Rbia & 0.0045 & 0 & & & & & & & \\
\hline Unio gibbus & 4 - Beth, Sebou & 0.0064 & 0.0091 & 0.0091 & & & & & & \\
\hline Unio gibbus & 5 - Mda & 0.0054 & 0.0081 & 0.0081 & 0.0024 & & & & & \\
\hline Unio gibbus & 6 - Barbate, Spain & 0.0045 & 0.0018 & 0.0018 & 0.0073 & 0.0063 & & & & \\
\hline Unio gibbus & 7 - Nefifikh & 0.0059 & 0.0066 & 0.0066 & 0.0054 & 0.0044 & 0.0057 & & & \\
\hline Unio gibbus & 8 - Tunisia & 0.0221 & 0.0212 & 0.0212 & 0.0204 & 0.0209 & 0.0194 & 0.0225 & & \\
\hline
\end{tabular}

haplotypes - Fig. 4).

\subsubsection{Unio gibbus}

Unio gibbus seems to have a higher resilience to wide-ranging climatic shifts when compared with $U$. foucauldianus, given the higher genetic diversity in spite of a narrower distribution (Figs. 4 and 5 and Table 3). The nesting of the Spanish haplotype within Moroccan ones, and the very restricted current and historical distribution in Southern Spain (Araujo et al., 2010; Lopes-Lima et al., 2017), suggest that Maghreb was the origin of Iberia's colonization (Fig. 5). The close genetic proximity between Spanish and Moroccan haplotypes (uncorrected $p$-distance $0.18 \%-0.73 \%$ - Table 2) suggests a colonization much more recent than the last land bridge between North Africa and Iberian Peninsula (i.e. 5.6 Mya). This raises the possibility of a humanmediated introduction through fish host or mussel translocations. Anthropogenic mediated introductions of other taxa in South West Europe from Morocco have already been reported (e.g. mammals Dobson, 1998; and amphibians Recuero et al., 2007). This hypothesis should be further investigated as it may have implications in the application of conservation actions for this species in Spain.

\subsection{Conservation}

Occupancy parameters (EOO and AOO) are expected to be heavily influenced by river intermittence. The low differences here reported (below 13\%) are probably an effect of sparse sampling and our conservative estimation of species distribution ranges. Given that we considered as potential presence only the river sections between two confirmed presence points, the base range was already biased towards large rivers, which are more likely to be permanent. Studies with finer sampling, or using taxa that occur in smaller rivers, are still expected to benefit greatly from river intermittence maps. Constructing maps of river intermittence will have important conservation and management implications at a worldwide scale. Intermittent rivers are among the freshwater ecosystems that receive less conservation attention and are generally poorly managed (Leigh et al., 2016, 2019). These systems tend to be overlooked by countries' authorities and, in some cases, not even legally recognised as part of the river network (Acuña et al., 2014;
Marshall et al., 2018). The generalized disregard of these systems partially results from inefficient characterization of water flow regimes associated with being ungauged, unmapped, or inaccurately depicted in topographic maps (Datry et al., 2014, 2017). Generating typologies that represent the natural heterogeneity of intermittent rivers is crucial to guide adequate management planning in both time and space and ensure restoration of the natural flow regimes (Datry et al., 2017). Identifying permanent water section refuges and ensure the undisrupted connectivity during flow seasons is essential for the long term survival and recovery of aquatic communities (Karaouzas et al., 2018). The results here presented clearly show the potential of combining topographically-derived hydrographic networks with the open source satellite imageries to create a realistic depiction of the intermittent river networks. Moreover, this strategy can be easily replicated in any river network and, given the high quality and quantity of satellite imagery available, it can even be applied at different spatial and temporal scales.

Regarding the EOO and AOO calculations, the higher sensitivity of the buffer strategies to differentiate between total and permanent-only river networks indicate an advantage. Furthermore, the 1 and $2 \mathrm{~km}$ buffers are a gross over-estimation of most mean river widths and therefore of the distribution range of aquatic species, and even some riparian species. The use of the 1 or $2 \mathrm{~km}$ standard buffer can greatly underestimate the threat status of many species, as observed in Table 4 and Fig. 9. Therefore, we propose here that for riverine species, AOO and EOO should be estimated with the mean length of the considered river network and not by the fixed grid or buffer area.

Transposing our approach of $\mathrm{AOO}$ and $\mathrm{EOO}$ estimation from a regional demonstration to a global implementation can have a fundamental impact on freshwater species preservation. Being the most globally relevant list of species at risk of extinction (Cardoso et al., 2011b), the IUCN Red List assessments have a fundamental role in guiding conservation efforts and funding, prioritizing protection acts, evaluating site irreplaceability and vulnerability, mobilizing environmental policies and legislation and monitoring biodiversity (Cardoso et al., 2011b; Carrizo et al., 2017 and references within). Thus, realistically assigning species conservation status must be a primary concern.

Considering the high species richness found in Northern rivers (Fig. 7), where all five native species are present, it is clear that these 
Table 3

Summary of indices of genetic diversity estimated from the COI sequencing data for all populations all species: sample size (N), number of haplotypes (h), haplotype diversity (Hd), nucleotide diversity $(\pi)$. Values of test of growth within each specie, i.e. the results of Fu's Fs and Tajima's D neutrality test. Statistically significant values are followed by an asterisk ( $p<0.05$ for Tajima's D and $p<0.02$ for Fu' Fs).

\begin{tabular}{|c|c|c|c|c|c|c|c|}
\hline Species & Haplogroup/populations & $N$ & $h$ & $\mathrm{Hd}$ & $\pi$ & Fu's FS & Tajima's D \\
\hline Anodonta anatina & European & 72 & 17 & 0.758 & 0.00641 & -4.98025 & -0.28149 \\
\hline Anodonta anatina & Italy/Ebro & 41 & 8 & 0.734 & 0.00403 & -1.16817 & -0.17893 \\
\hline Anodonta anatina & South West Iberia & 15 & 6 & 0.648 & 0.00141 & $-3.61846^{*}$ & $-1.66013 *$ \\
\hline Anodonta anatina & South Central Iberia & 14 & 5 & 0.791 & 0.00398 & 0.32272 & -0.45993 \\
\hline Anodonta anatina & North West Iberia & 37 & 11 & 0.803 & 0.00256 & $-5.4955^{*}$ & $-1.57827^{*}$ \\
\hline Anodonta anatina & Morocco & 12 & 1 & 0 & 0 & - & - \\
\hline Pseudunio marocanus & Boulhou & 12 & 2 & 0.303 & 0.00046 & 0.297 & -0.19492 \\
\hline Pseudunio marocanus & Oum Er Rbia basin & 10 & 4 & 0.711 & 0.00203 & -0.277 & -0.21888 \\
\hline Pseudunio marocanus & All Moroccan distribution & 22 & 6 & 0.745 & 0.00213 & -1.107 & 0.06716 \\
\hline Potomida littoralis & Martil & 6 & 3 & 0.733 & 0.00139 & -0.42679 & -0.05002 \\
\hline Potomida littoralis & Massa & 2 & 2 & 0 & 0 & - & - \\
\hline Potomida littoralis & Oum Er Rbia & 23 & 9 & 0.858 & 0.00633 & -0.50165 & 0.318 \\
\hline Potomida littoralis & Sebou & 25 & 9 & 0.683 & 0.00192 & $-5.1001^{*}$ & $-1.65639 *$ \\
\hline Potomida littoralis & Laou & 4 & 1 & 0 & 0 & - & - \\
\hline Potomida littoralis & Draa & 13 & 1 & 0 & 0 & - & - \\
\hline Potomida littoralis & Ziz & 13 & 1 & 0 & 0 & - & - \\
\hline Potomida littoralis & Souss & 10 & 1 & 0 & 0 & - & - \\
\hline Potomida littoralis & Tunisia & 18 & 5 & 0.68 & 0.00288 & 0.23226 & 0.74839 \\
\hline Potomida littoralis & All Moroccan distribution & 114 & 26 & 0.887 & 0.00857 & -4.45264 & -0.54629 \\
\hline Unio foucauldianus & Mda & 12 & 5 & 0.667 & 0.00146 & $-2.14438^{*}$ & -1.10317 \\
\hline Unio foucauldianus & Sebou & 33 & 5 & 0.491 & 0.00087 & $-2.15389^{*}$ & -1.11821 \\
\hline Unio foucauldianus & Oum Er Rbia & 8 & 1 & 0 & 0 & - & - \\
\hline Unio foucauldianus & Noun & 6 & 2 & 0.333 & 0.00053 & -0.00275 & -0.93302 \\
\hline Unio foucauldianus & Massa & 6 & 1 & 0 & 0 & - & - \\
\hline Unio foucauldianus & Tensift & 6 & 1 & 0 & 0 & - & - \\
\hline Unio foucauldianus & Moulouya & 8 & 1 & 0 & 0 & - & - \\
\hline Unio foucauldianus & Martil & 8 & 2 & 0.25 & 0.0004 & -0.18197 & -1.05482 \\
\hline Unio foucauldianus & Loukos & 9 & 4 & 0.694 & 0.00232 & -1.26031 & -0.91004 \\
\hline Unio foucauldianus & Bouregreg & 16 & 2 & 0.500 & 0.00080 & 1.24657 & 1.30896 \\
\hline Unio foucauldianus & Lou & 3 & 1 & 0 & 0 & - & - \\
\hline Unio foucauldianus & Nefifikh & 6 & 2 & 0.333 & 0.00160 & 1.60944 & -1.23311 \\
\hline Unio foucauldianus & All Moroccan distribution & 121 & 14 & 0.566 & 0.00173 & $-9.13433^{*}$ & $-1.56240 *$ \\
\hline Unio gibbus & Bouregreg & 4 & 2 & 0.667 & 0.00596 & 3.15252 & 2.12492 \\
\hline Unio gibbus & Noun & 6 & 1 & 0 & 0 & - & - \\
\hline Unio gibbus & Oum Er Rbia & 3 & 1 & 0 & 0 & - & - \\
\hline Unio gibbus & Beth, Sebou & 13 & 3 & 0.692 & 0.00151 & 0.43557 & 0.87897 \\
\hline Unio gibbus & Mda & 6 & 3 & 0.6 & 0.00179 & -0.18945 & -1.23311 \\
\hline Unio gibbus & Barbate, Spain & 7 & 1 & 0 & 0 & - & - \\
\hline Unio gibbus & Nefifikh & 19 & 3 & 0.602 & 0.00401 & 3.53364 & 1.75913 \\
\hline Unio gibbus & Tunisia & 7 & 4 & 0.81 & 0.00494 & 0.49468 & 0.64916 \\
\hline Unio gibbus & All Moroccan distribution & 51 & 9 & 0.827 & 0.00516 & 0.24080 & 0.85075 \\
\hline
\end{tabular}

Table 4

Areas of occupancy (AOO) and Extent of occurrence (EOO) values for the five freshwater mussel species of Morocco. Five strategies using either a buffer or square grids (UTM29) were applied to two river networks: total hydrosheds network, and permanent-rivers only. Cells are shaded according to the resulting conservation status according to IUCN Red List criterion B: yellow - Endangered; red - Critically endangered.

\begin{tabular}{|c|c|c|c|c|c|c|c|c|c|c|}
\hline & \multicolumn{10}{|c|}{ Calculated values of EOO and $\mathrm{AOO}\left(\mathrm{km}^{2}\right)$} \\
\hline & \multicolumn{2}{|c|}{ Anadonta anatina } & \multicolumn{2}{|c|}{ Potomida littoralis } & \multicolumn{2}{|c|}{ Unio foucauldianus } & \multicolumn{2}{|c|}{ Unio gibbus } & \multicolumn{2}{|c|}{ Pseudunio marocanus } \\
\hline & EOO & AOO & EOO & AOO & EOO & AOO & EOO & AOO & EOO & AOO \\
\hline $2 \times 2$ km grid - Permanent & 168 & 8 & 1748 & 120 & 2564 & 104 & 516 & 44 & 232 & 44 \\
\hline $2 \times 2 \mathrm{~km}$ grid - Total & 168 & 8 & 1772 & 120 & 2600 & 104 & 532 & 44 & 232 & 44 \\
\hline 2 km buffer - Permanent & 169 & 8 & 1569 & 124 & 2246 & 108 & 398 & 52 & 185 & 52 \\
\hline 2 km buffer - Total & 169 & 8 & 1616 & 124 & 2323 & 108 & 449 & 52 & 184 & 52 \\
\hline $1 \times 1 \mathrm{~km}$ grid - Permanent & 91 & 2 & 887 & 30 & 1302 & 27 & 237 & 11 & 106 & 12 \\
\hline $1 \times 1 \mathrm{~km}$ grid - Total & 91 & 2 & 908 & 30 & 1329 & 27 & 253 & 11 & 106 & 12 \\
\hline $1 \mathrm{~km}$ buffer - Permanent & 83 & 2 & 780 & 31 & 1118 & 27 & 197 & 13 & 91 & 13 \\
\hline 1 km buffer - Total & 83 & 2 & 803 & 31 & 1156 & 27 & 222 & 13 & 91 & 13 \\
\hline River length $\times$ width - Permanent & 4.16 & 0.02 & 54.17 & 0.48 & 63.91 & 0.28 & 5.61 & 0.08 & 3.52 & 0.08 \\
\hline River length $\times$ width - Total & 4.17 & 0.02 & 55.87 & 0.48 & 65.62 & 0.28 & 6.01 & 0.08 & 3.52 & 0.08 \\
\hline
\end{tabular}




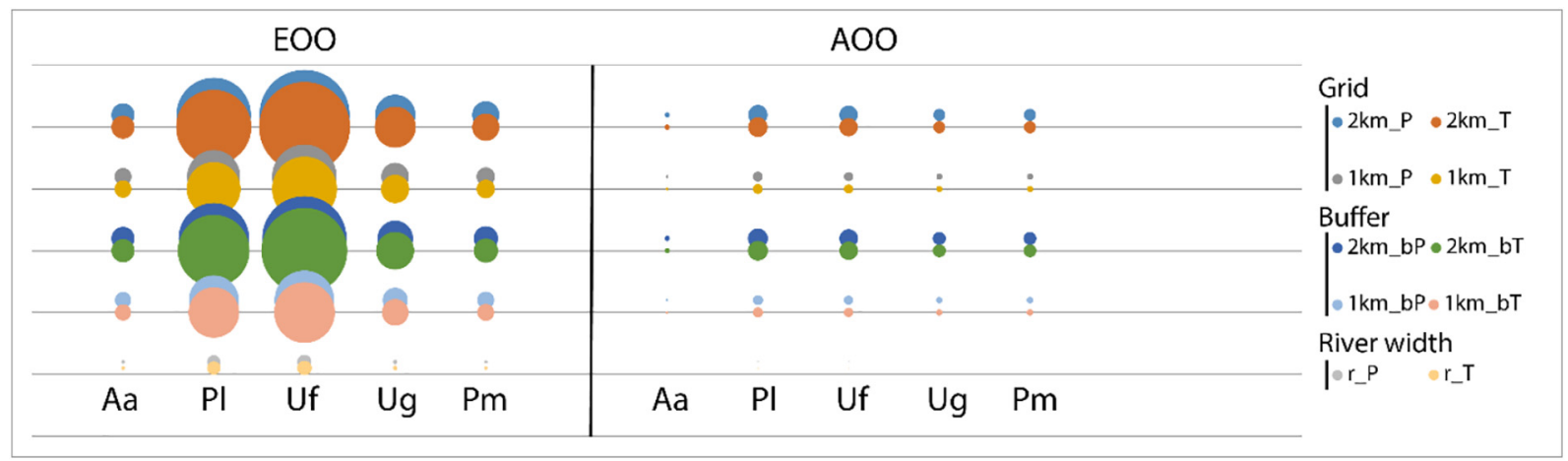

Fig. 9. Areas of occupancy (AOO) and extent of occurrence (EOO) values for the five freshwater mussel species of Morocco: $A$. anatina (Aa), $P$. littoralis (Pl), $U$. foucauldianus (Uf), $U$ gibbus (Ug) and P. marocanus (Pm). Five strategies were applied to two river networks - total Hydrosheds network (T), and permanent-rivers (P); and using either a buffer or square grids (UTM29) - $2 \mathrm{~km}$ grid ( $2 \mathrm{~km}), 1 \mathrm{~km}$ grid (1 km), $2 \mathrm{~km}$ buffer (b $2 \mathrm{~km})$ and $1 \mathrm{~km}$ buffer (b $1 \mathrm{~km})$ along river length, and river width $*$ length $(\mathrm{r})$.

areas represent broad priority areas for conservation of freshwater mussels. However, protecting some of the southern basins is paramount to safeguard phylogenetically unique populations.

Anodonta anatina in Morocco is likely restricted to Oum Er Rbia and Loukos basins, since the old records from Bouregreg/Grou River were not confirmed, and only shells were found in Mda. Based on the estimated EOO and AOO the species is here listed as Critically Endangered in Morocco B1ab(i,ii,iii,iv), B2ab(i,ii,iii,iv) (Table 4; see Appendix A for complete assessment). The species is very common in Europe, colonizing a wide variety of habitats (Hinzmann et al., 2013; Lopes-Lima et al., 2017). So it is unclear if the phylogeographic distinctiveness of the Moroccan populations warrants a CR status. The latter could possess unique adaptations to aridity (invaluable when considering future climate scenarios), but that is still speculative.

Potomida littoralis, widely distributed in South-west Europe and in Maghreb region, was recently listed as Endangered, globally (LopesLima et al., 2014a). This species is widely distributed in Morocco, but most of the populations are highly fragmented, in some cases occurring in one location within each basin. The populations from Draa and Ziz basins (Fig. 3), relicts from the Green Sahara, present high genetic and phylogeographic uniqueness and should receive particular conservation attention. Based on the estimated EOO and AOO the species is here listed as Critically Endangered in Morocco B1ab(i,ii,iii,iv), B2ab (i,ii,iii,iv) (Table 4; see Appendix A for complete assessment).

Unio foucauldianus is still listed as Critically Endangered by the IUCN (Van Damme and Ghamizi, 2010b) but has been in need of conservation status reassessment since the results of a recent taxonomic revision revealing the species distribution to be wider than previously believed (Froufe et al., 2016a). In fact, the present study confirms that $U$. foucauldianus is present in several basins, although the distribution seems highly fragmented (often one population per basin). In spite of the recently proposed IUCN conservation status down-listing of $U$. foucauldianus (Froufe et al., 2016a), the reassessment of the species still resulted in Critically Endangered B1ab(i,ii,iii,iv), B2ab(i,ii,iii,iv) status due to the very low estimated EOO and AOO (Table 4; see Appendix A for complete assessment). Populations from Bouregreg and Nefifikh basins are of particular interest given their genetical distinctiveness.

Unio gibbus is present from Morocco to Tunisia and in Southern Spain, where only a small population persists. For this reason, the species is listed as Critical Endangered in Europe (Araujo, 2011). In Morocco, $U$. gibbus is present in several basins, although the distribution is highly fragmented (mostly one population per major basin). The species abundance is generally low across all sites (e.g. 3 individuals across the many sampling sites in Oum Er Rbia), and mainly occurs in downstream areas where it is highly exposed to human disturbance. The species is here assessed as Critically Endangered in Morocco B1ab (i,ii,iii,iv), B2ab(i,ii,iii,iv) due to the very low estimated AOO and EOO
(Table 4; see Appendix A for complete assessment). Bouregreg and Nefifikh basins should receive particular attention; the first given the apparent poor status of the population (four individuals found) and their high diversity; and the second due to genetic distinctiveness.

Pseudunio marocanus is currently listed as Critically Endangered based on its dramatic decline over the last one hundred years, being currently restricted to two basins (Oum Er Rbia and Sebou; Sousa et al., 2016, 2018). Pseudunio marocanus represents an obvious conservation priority. Shells found in Moulouya River could indicate the presence of an undocumented population in this river (Fig. 6), so additional surveys are urgently needed. Meanwhile, considering EOO and AOO values (Table 4), is here listed as Critically Endangered B1ab(i,ii,iii,iv), B2ab (i,ii,iii,iv) globally and in Morocco (see Appendix A for complete assessment).

\subsection{Conclusions}

This work substantially increases the present knowledge about the current distribution and phylogeographic patterns of freshwater mussels in a poorly studied area, where freshwater ecosystems are particularly threatened by water shortage and increasing aridity. Here we show that the permanent sections correspond to only $18.3 \%$ of the whole hydrographic network of Morocco. Scientific studies and conservation plans need to consider the water-body intermittence and not rely solely in topographically-derived hydrographic networks, particularly in arid and semi-arid regions. Using standard (1-2 km) square grids to evaluate freshwater taxa may highly underestimate the threat status, and we propose the mean river width as a more sensible approach that requires a minimal increase in effort. Using tailored approaches to each ecosystem is technically feasible and urgently needed in order to anticipate the effects of climate and land- and water-use changes and effectively protect the highly threatened freshwater taxa.

Supplementary data to this article can be found online at https:// doi.org/10.1016/j.biocon.2019.05.038.

\section{Acknowledgments}

This work was partially supported by the Portuguese Foundation for Science and Technology (FCT) under grant SFRH/BD/115728/2016 (MLL) and grant SFRH/BD/137935/2018 (AGS). This research was developed under ConBiomics: the missing approach for the Conservation of freshwater Bivalves Project $\mathrm{N}^{\circ}$ NORTE-01-0145FEDER-030286, co-financed by COMPETE 2020, Portugal 2020 and the European Union through the ERDF, and by FCT through national funds. This study was additionally conducted within the scope of project "Biodiversity and conservation of the critically endangered freshwater mussels in Morocco: ecogeographic, genetic and physiological 
information", funded by Mohamed bin Zayed Species Conservation Fund (Reference 15256799) and project "Breeding the most endangered bivalve on Earth: Margaritifera marocana", funded by IUCN SOS save our species fund (Reference 2015B-015). Official capture and sampling licenses were issued by the Université Cadi Ayyad (Faculté des Sciences, Semlalia, Marrakech, Maroc).

\section{References}

Acuña, V., Datry, T., Marshall, J., Barceló, D., Dahm, C.N., Ginebreda, A., McGregor, G., Sabater, S., Tockner, K., Palmer, M.A., 2014. Why should we care about temporary waterways? Science (80-.) 343, 1080 LP-1081. https://doi.org/10.1126/science. 1246666.

Araujo, R., 2011. Unio Gibbus. The IUCN Red List of Threatened Species 2011: e.T171953A6812362. (Downloaded on 01 March 2019).

Araujo, R., Toledo, C., Van Damme, D., Ghamizi, M., MacHordom, A., 2009. Margaritifera marocana (Pallary, 1918): a valid species inhabiting Moroccan rivers. J. Molluscan Stud. 75, 95-101. https://doi.org/10.1093/mollus/eyn043.

Araujo, R., Toledo, C., Machordom, A., 2010. Redescription of Unio gibbus Spengler, 1793, a west palaearctic freshwater mussel with Hookless Glochidia. Malacologia 51, 131-141. https://doi.org/10.4002/040.051.0109.

Araujo, R., Buckley, D., Nagel, K.O., Machordom, A., 2016. Potomida littoralis (Bivalvia, Unionidae) evolutionary history: slow evolution or recent speciation? Zool. J. Linnean Soc. 179 (2), 277-290. https://doi.org/10.1111/zoj.12470.

Balian, E.V., Segers, H., Lévèque, C., Martens, K., 2008. The freshwater animal diversity assessment: an overview of the results. Hydrobiologia. https://doi.org/10.1007/ s10750-007-9246-3.

Beddek, M., Zenboudji-Beddek, S., Geniez, P., Fathalla, R., Sourouille, P., Arnal, V., Dellaoui, B., Koudache, F., Telailia, S., Peyre, O., Crochet, P.A., 2018. Comparative phylogeography of amphibians and reptiles in Algeria suggests common causes for the east-west phylogeographic breaks in the Maghreb. PLoS One 13, e0201218. https://doi.org/10.1371/journal.pone.0201218.

Bernhardt, E.S., Palmer, M.A., 2011. River restoration: the fuzzy logic of repairing reaches to reverse catchment scale degradation. Ecol. Appl. https://doi.org/10.1890/101574.1.

Bolotov, I.N., Vikhrev, I.V., Bespalaya, Y.V., Gofarov, M.Y., Kondakov, A.V., Konopleva, E.S., Bolotov, N.N., Lyubas, A.A., 2016. Multi-locus fossil-calibrated phylogeny, biogeography and a subgeneric revision of the Margaritiferidae (Mollusca: Bivalvia: Unionoida). Mol. Phylogenet. Evol. 103, 104-121. https://doi.org/10.1016/j.ympev. 2016.07.020.

Brito, J.C., Godinho, R., Martínez-Freiría, F., Pleguezuelos, J.M., Rebelo, H., Santos, X., Vale, C.G., Velo-Antón, G., Boratyński, Z., Carvalho, S.B., Ferreira, S., Gonçalves, D.V., Silva, T.L., Tarroso, P., Campos, J.C., Leite, J.V., Nogueira, J., Álvares, F., Sillero, N., Sow, A.S., Fahd, S., Crochet, P.A., Carranza, S., 2014. Unravelling biodiversity, evolution and threats to conservation in the Sahara-Sahel. Biol. Rev. 89, 215-231. https://doi.org/10.1111/brv.12049.

Cardoso, P., Erwin, T.L., Borges, P.A.V., New, T.R., 2011a. The seven impediments in invertebrate conservation and how to overcome them. Biol. Conserv. 144, 2647-2655. https://doi.org/10.1016/j.biocon.2011.07.024.

Cardoso, P., Borges, P.A.V., Triantis, K.A., Ferrández, M.A., Martín, J.L., 2011b. Adapting the IUCN red list criteria for invertebrates. Biol. Conserv. 144, 2432-2440. https:// doi.org/10.1016/J.BIOCON.2011.06.020.

Carpenter, S.R., Stanley, E.H., Vander Zanden, M.J., 2011. State of the world's freshwater ecosystems: physical, chemical, and biological changes. Annu. Rev. Environ. Resour. 36, 75-99. https://doi.org/10.1146/annurev-environ-021810-094524.

Carrizo, S.F., Lengyel, S., Kapusi, F., Szabolcs, M., Kasperidus, H.D., Scholz, M., Markovic, D., Freyhof, J., Cid, N., Cardoso, A.C., Darwall, W., 2017. Critical catchments for freshwater biodiversity conservation in Europe: identification, prioritisation and gap analysis. J. Appl. Ecol. 54, 1209-1218. https://doi.org/10.1111/1365-2664.12842.

Clavero, M., Esquivias, J., Qninba, A., Riesco, M., Calzada, J., Ribeiro, F., Fernández, N., Delibes, M., 2015. Fish invading deserts: non-native species in arid Moroccan rivers. Aquat. Conserv. Mar. Freshw. Ecosyst. 25, 49-60. https://doi.org/10.1002/aqc. 2487.

Clavero, M., Calzada, J., Esquivias, J., Veríssimo, A., Hermoso, V., Qninba, A., Delibes, M., 2017. Nowhere to swim to: climate change and conservation of the relict Dades trout Salmo multipunctata in the High Atlas Mountains, Morocco. Oryx 52, 1-9. https://doi.org/10.1017/S0030605316001551.

Clement, M., Posada, D., Crandall, K.A., 2000. TCS: a computer program to estimate gene genealogies. Mol. Ecol. 9, 1657-1659. https://doi.org/10.1046/j.1365-294x.2000. 01020.x.

Cummings, K.S., Jones, H.A., Lopes-Lima, M., 2016. Rapid bioassessment methods for freshwater Molluscs. In: Core Standardized Methods for Rapid Biological Field Assessment, pp. 185-207. https://doi.org/10.1038/s41598-017-09909-4.

Daget, J., 1998. Catalogue raisonné des Mollusques bivalves d'eau douce africains. Backhuys Publishers, Orstom Leiden, Paris.

Darriba, D., Taboada, G.L., Doallo, R., Posada, D., 2012. JModelTest 2: more models, new heuristics and parallel computing. Nat. Methods 9, 772. https://doi.org/10.1038/ nmeth.2109.

Datry, T., Larned, S.T., Tockner, K., 2014. Intermittent rivers: a challenge for freshwater ecology. Bioscience 64, 229-235. https://doi.org/10.1093/biosci/bit027.

Datry, T., Bonada, N., Boulton, A.J., 2017. Intermittent Rivers and Ephemeral Streams, Intermittent Rivers and Ephemeral Streams. https://doi.org/10.1016/c2015-000459-2.

Dobson, M., 1998. Mammal distributions in the western Mediterranean: the role of human intervention. Mamm. Rev. 28, 77-88. https://doi.org/10.1046/j.1365-2907. 1998.00027x.

Drake, N.A., Blench, R.M., Armitage, S.J., Bristow, C.S., White, K.H., 2011. Ancient watercourses and biogeography of the Sahara explain the peopling of the desert. Proc. Natl. Acad. Sci. 108, 458-462. https://doi.org/10.1073/pnas.1012231108.

Dudgeon, D., Arthington, A.H., Gessner, M.O., Kawabata, Z.I., Knowler, D.J., Lévêque, C., Naiman, R.J., Prieur-Richard, A.H., Soto, D., Stiassny, M.L.J., Sullivan, C.A., 2006. Freshwater biodiversity: importance, threats, status and conservation challenges. Biol. Rev. Camb. Philos. Soc. https://doi.org/10.1017/S1464793105006950.

Excoffier, L., Lischer, H.E.L., 2010. Arlequin suite ver 3.5: a new series of programs to perform population genetics analyses under Linux and Windows. Mol. Ecol. Resour. 10, 564-567. https://doi.org/10.1111/j.1755-0998.2010.02847.x.

Ferreira-Rodríguez, N., Akiyama, Y.B., Aksenova, O.V., Araujo, R., Christopher Barnhart, M., Bespalaya, Y.V., Bogan, A.E., Bolotov, I.N., Budha, P.B., Clavijo, C., Clearwater, S.J., Darrigran, G., Do, V.T., Douda, K., Froufe, E., Gumpinger, C., Henrikson, L., Humphrey, C.L., Johnson, N.A., Klishko, O., Klunzinger, M.W., Kovitvadhi, S., Kovitvadhi, U., Lajtner, J., Lopes-Lima, M., Moorkens, E.A., Nagayama, S., Nagel, K.O., Nakano, M., Negishi, J.N., Ondina, P., Oulasvirta, P., Prié, V., Riccardi, N., Rudzīte, M., Sheldon, F., Sousa, R., Strayer, D.L., Takeuchi, M., Taskinen, J., Teixeira, A., Tiemann, J.S., Urbańska, M., Varandas, S., Vinarski, M.V., Wicklow, B.J., Zając, T., Vaughn, C.C., 2019. Research priorities for freshwater mussel conservation assessment. Biol. Conserv. 231, 77-87. https://doi.org/10.1016/J.BIOCON.2019.01. 002.

Froufe, E., Sobral, C., Teixeira, A., Sousa, R., Varandas, S., Aldridge, D.C., Lopes-Lima, M., 2014. Genetic diversity of the pan-European freshwater mussel Anodonta anatina (Bivalvia: Unionoida) based on CO1: New phylogenetic insights and implications for conservation. Aquat. Conserv. Mar. Freshw. Ecosyst. 24, 561-574. https://doi.org/ 10.1002/aqc. 2456

Froufe, E., Gonçalves, D.V., Teixeira, A., Sousa, R., Varandas, S., Ghamizi, M., Zieritz, A., Lopes-Lima, M., 2016a. Who lives where? Molecular and morphometric analyses clarify which Unio species (Unionida, Mollusca) inhabit the southwestern Palearctic. Org. Divers. Evol. 16, 597-611. https://doi.org/10.1007/s13127-016-0262-x.

Froufe, E., Prié, V., Faria, J., Ghamizi, M., Gonçalves, D.V., Gürlek, M.E., Karaouzas, I., Kebapçi, Ü., Şereflişan, H., Sobral, C., Sousa, R., Teixeira, A., Varandas, S., Zogaris, S. Lopes-Lima, M., 2016b. Phylogeny, phylogeography, and evolution in the Mediterranean region: news from a freshwater mussel (Potomida, Unionida). Mol. Phylogenet. Evol. 100, 322-332. https://doi.org/10.1016/j.ympev.2016.04.030.

Froufe, E., Lopes-Lima, M., Riccardi, N., Zaccara, S., Vanetti, I., Lajtner, J., Teixeira, A., Varandas, S., Prié, V., Zieritz, A., Sousa, R., Bogan, A.E., 2017. Lifting the curtain on the freshwater mussel diversity of the Italian Peninsula and Croatian Adriatic coast. Biodivers. Conserv. 26, 3255-3274. https://doi.org/10.1007/s10531-017-1403-z.

Graf, D.L., Cummings, K.S., 2007. Review of the systematics and global diversity of freshwater mussel species (Bivalvia: Unionoida). J. Molluscan Stud. https://doi.org/ 10.1093/mollus/eym029.

Graf, D.L., Cummings, K.S., 2011. Freshwater mussel (Mollusca: Bivalvia: Unionoida) richness and endemism in the ecoregions of Africa and Madagascar based on com prehensive museum sampling. Hydrobiologia 678, 17-36. https://doi.org/10.1007/ s10750-011-0810-5.

Graf, D.L., Cummings, K.S., 2015. The freshwater mussels (Unionoida) of the world (and other less consequential bivalves) - MUSSEL project [WWW document]. URL. http:// mussel-project.uwsp.edu/.

Haas, F., 1969. Superfamilia Unionacea. In: Hennig, W. (Ed.), Das Tierreich. vol. Volume 88 De Gruyter, Berlin (in German).

Hall, T., 1999. BioEdit: A User-friendly Biological Sequence Alignment Editor and Analysis Program for Windows 95/98/NT.

Hinzmann, M., Lopes-Lima, M., Teixeira, A., Varandas, S., Sousa, R., Lopes, A., Froufe, E., Machado, J., 2013. Reproductive cycle and strategy of Anodonta anatina (L., 1758): notes on hermaphroditism. J. Exp. Zool. Part A Ecol. Genet. Physiol. 319, 378-390. https://doi.org/10.1002/jez.1801.

Husemann, M., Ray, J.W., King, R.S., Hooser, E.A., Danley, P.D., 2012. Comparative biogeography reveals differences in population genetic structure of five species of stream fishes. Biol. J. Linn. Soc. 107, 867-885. https://doi.org/10.1111/j.10958312.2012.01973.x.

Husemann, M., Schmitt, T., Zachos, F.E., Ulrich, W., Habel, J.C., 2014. Palaearctic biogeography revisited: evidence for the existence of a North African refugium for Western Palaearctic biota. J. Biogeogr. 41, 81-94. https://doi.org/10.1111/jbi. 12180.

IUCN, 2001. IUCN red list categories and criteria. Version 3.1. IUCN Species Survival Commission, Gland, Switzerland and Cambridge, UKhttps://www.iucnredlist.org/ static/categories_criteria_3_1.

Karaouzas, I., Theodoropoulos, C., Vardakas, L., Kalogianni, E., Th. Skoulikidis, N., 2018. A review of the effects of pollution and water scarcity on the stream biota of an intermittent Mediterranean basin. River Res. Appl. https://doi.org/10.1002/rra. 3254.

Khalloufi, N., Toledo, C., Machordom, A., Boumaïza, M., Araujo, R., 2011. The unionids of Tunisia: taxonomy and phylogenetic relationships, with redescription of Unio ravoisieri Deshayes, 1847 and U. durieui Deshayes, 1847. J. Molluscan Stud. 77, 103-115. https://doi.org/10.1093/mollus/eyq046.

Kingsford, R.T., Boulton, A.J., Puckridge, J.T., 1998. Challenges in managing dryland rivers crossing political boundaries: lessons from Cooper Creek and the Paroo River, Central Australia. Aquat. Conserv. Mar. Freshw. Ecosyst 8, 361-378. https://doi.org/ 10.1002/(SICI)1099-0755(199805/06)8:3 < 361::AID-AQC294 > 3.0.CO;2-V.

Klishko, O.K., Lopes-Lima, M., Bogan, A.E., Matafonov, D.V., Froufe, E., 2018. Morphological and molecular analyses of Anodontinae species (Bivalvia, Unionidae) of Lake Baikal and Transbaikalia. PLoS One 13, e0194944. https://doi.org/10.1371/ journal.pone.0194944. 
Kumar, S., Stecher, G., Tamura, K., 2016. MEGA7: molecular evolutionary genetics analysis version 7.0 for bigger datasets. Mol. Biol. Evol. 33, 1870-1874. https://doi. org/10.1093/molbev/msw054.

Le Houérou, H.N., 1992. Outline of the biological history of the Sahara. J. Arid Environ. 22, 3-30. https://doi.org/10.1016/S0140-1963(18)30653-0.

Lehner, B., Grill, G., 2013. Global river hydrography and network routing: baseline data and new approaches to study the world's large river systems. Hydrol. Process. 27, 2171-2186. https://doi.org/10.1002/hyp.9740.

Lehner, B., Verdin, K., Jarvis, A., 2008. New global hydrography derived from spaceborne elevation data. Eos (Washington. DC) 89, 93-94. https://doi.org/10.1029/ 2008EO100001.

Leigh, C., Boulton, A.J., Courtwright, J.L., Fritz, K., May, C.L., Walker, R.H., Datry, T., 2016. Ecological research and management of intermittent rivers: an historical review and future directions. Freshw. Biol. 61, 1181-1199. https://doi.org/10.1111/ fwb. 12646 .

Leigh, C., Boersma, K.S., Galatowitsch, M.L., Milner, V.S., Stubbington, R., 2019. Are all rivers equal? The role of education in attitudes towards temporary and perennial rivers. People Nat., pan3.22. https://doi.org/10.1002/pan3.22.

Lopes-Lima, M., Prie, V., Seddon, M.B., 2014a. Potomida littoralis. The IUCN Red List of Threatened Species 2014. e.T156136A42423034. Downloaded on 01 March 2019. https://doi.org/10.2305/IUCN.UK.2014- 1.RLTS.T15.

Lopes-Lima, M., Teixeira, A., Froufe, E., Lopes, A., Varandas, S., Sousa, R., 2014b. Biology and conservation of freshwater bivalves: past, present and future perspectives. Hydrobiologia. https://doi.org/10.1007/s10750-014-1902-9.

Lopes-Lima, M., Sousa, R., Geist, J., Aldridge, D.C., Araujo, R., Bergengren, J., Bespalaya, Y., Bódis, E., Burlakova, L., Van Damme, D., Douda, K., Froufe, E., Georgiev, D., Gumpinger, C., Karatayev, A., Kebapçi, Ü., Killeen, I., Lajtner, J., Larsen, B.M Lauceri, R., Legakis, A., Lois, S., Lundberg, S., Moorkens, E., Motte, G., Nagel, K.O., Ondina, P., Outeiro, A., Paunovic, M., Prié, V., von Proschwitz, T., Riccardi, N., Rudzīte, M., Rudzītis, M., Scheder, C., Seddon, M., Şereflişan, H., Simić, V., Sokolova, S., Stoeckl, K., Taskinen, J., Teixeira, A., Thielen, F., Trichkova, T., Varandas, S., Vicentini, H., Zajac, K., Zajac, T., Zogaris, S., 2017. Conservation status of freshwater mussels in Europe: state of the art and future challenges. Biol. Rev. 92, 572-607. https://doi.org/10.1111/brv.12244.

Lopes-Lima, M., Burlakova, L.E., Karatayev, A.Y., Mehler, K., Seddon, M., Sousa, R., 2018. Conservation of freshwater bivalves at the global scale: diversity, threats and research needs. Hydrobiologia 810, 1-14. https://doi.org/10.1007/s10750-017-3486-7.

Lydeard, C., Cowie, R.H., Ponder, W.F., Bogan, A.E., Bouchet, P., Clark, S.A., Cummings, K.S., Frest, T.J., Gargominy, O., Herbert, D.G., Herchler, R., Perez, K.E., Roth, B., Seddon, M., Strong, E.E., Thompson, F.G., 2004. The global decline of nonmarine mollusks. Bioscience 54, 321-330. https://doi.org/10.1641/0006-3568(2004) 054[0321:TGDONM]2.0.CO;2.

Machordom, A., Doadrio, I., 2001. Evidence of a Cenozoic Betic-Kabilian connection based on freshwater fish phylogeography (Luciobarbus, Cyprinidae). Mol. Phylogenet. Evol. 18, 252-263. https://doi.org/10.1006/mpev.2000.0876.

Mandhal-Barth, G., 1988. Studies on African Freshwater Bivalves. Danish Bilharziasis Laboratory, Charlottenlund Denmark.

Marshall, J.C., Acuña, V., Allen, D.C., Bonada, N., Boulton, A.J., Carlson, S.M., Dahm, C.N., Datry, T., Leigh, C., Negus, P., Richardson, J.S., Sabater, S., Stevenson, R.J., Steward, A.L., Stubbington, R., Tockner, K., Vander Vorste, R., 2018. Protecting U.S. temporary waterways. Science 361, 856-857. https://doi.org/10.1126/science. aav0839.

Múrias Dos Santos, A., Cabezas, M.P., Tavares, A.I., Xavier, R., Branco, M., 2015. TcsBU: a tool to extend TCS network layout and visualization. Bioinformatics 32, 627-628. https://doi.org/10.1093/bioinformatics/btv636.

Myers, N., Mittermeler, R.A., Mittermeler, C.G., Da Fonseca, G.A.B., Kent, J., 2000 Biodiversity hotspots for conservation priorities. Nature 403, 853-858. https://doi. org/10.1038/35002501.

Naimo, T.J., Damschen, E.D., Rada, R.G., Monroe, E.M., 1998. Nonlethal evaluation of the physiological health of Unionid mussels: methods for biopsy and glycogen analysis. J. North Am. Benthol. Soc. 17, 121-128. https://doi.org/10.2307/1468056.

Pallary, P., 1918. Diagnoses d'une cinquantaine de Mollusques terrestres nouveaux du Nord de l'Afrique. Bull. la Société d'Histoire Nat. l'Afrique du Nord 9, 137-152.

Pallary, P., 1923. Descriptions de trois Mollusques nouveaux du Maroc. Bull. la Société des Sci. Nat. du Maroc 3, 78-79.

Pallary, P., 1928. Notice sur seize Mollusques nouveaux du Maroc découverts en 1926 et 1927. J. Conchyliol. 1-24.

Prendergast, A.L., Stevens, R.E., O'Connell, T.C., Hill, E.A., Hunt, C.O., Barker, G.W., 2016. A late Pleistocene refugium in Mediterranean North Africa? Palaeoenvironmental reconstruction from stable isotope analyses of land snail shells (Haua Fteah, Libya). Quat. Sci. Rev. 139, 94-109. https://doi.org/10.1016/j quascirev. 2016.02.014.

Rambaut, A., Drummond, A.J., Xie, D., Baele, G., Suchard, M.A., 2018. Posterior summarization in Bayesian phylogenetics using tracer 1.7. Syst. Biol. 67, 901-904. https://doi.org/10.1093/sysbio/syy032.

Recuero, E., Iraola, A., Rubio, X., Machordom, A., García-París, M., 2007. Mitochondrial differentiation and biogeography of Hyla meridionalis (Anura: Hylidae): an unusual phylogeographical pattern. J. Biogeogr. 34, 1207-1219. https://doi.org/10.1111/j. 1365-2699.2007.01688x.

Reid, A.J., Carlson, A.K., Creed, I.F., Eliason, E.J., Gell, P.A., Johnson, P.T.J., Kidd, K.A., MacCormack, T.J., Olden, J.D., Ormerod, S.J., Smol, J.P., Taylor, W.W., Tockner, K., Vermaire, J.C., Dudgeon, D., Cooke, S.J., 2019. Emerging threats and persistent conservation challenges for freshwater biodiversity. Biol. Rev. https://doi.org/10. 1111/brv. 12480

Reis, J., Machordom, A., Araujo, R., 2013. Diversidad morfológica y molecular de los Unionidae (Mollusca, Bivalvia) de Portugal. Graellsia 69, 17-36. https://doi.org/10. 3989/graellsia.2013.v69.075.

Ronquist, F., Teslenko, M., van der Mark, P., Ayres, D.L., Darling, A., Höhna, S., Larget, B., Liu, L., Suchard, M.A., Huelsenbeck, J.P., 2012. MrBayes 3.2: efficient Bayesian phylogenetic inference and model choice across a large model space. Syst. Biol. 61, 539-542. https://doi.org/10.1093/sysbio/sys029.

Rozas, J., Rozas, R., 1995. DnaSP, DNA sequence polymorphism: an interactive program for estimating population genetics parameters from DNA sequence data. Bioinformatics 11, 621-625. https://doi.org/10.1093/bioinformatics/11.6.621.

Sambrook, J., Russell, D.W., Maniatis, T., 1989. Molecular Cloning : A Laboratory Manual. Cold Spring Harbor Laboratory Press, New York, NY.

Sarnthein, M., 1978. Sand deserts during glacial maximum and climatic optimum. Nature 272, 43-46. https://doi.org/10.1038/272043a0.

Schilling, J., Freier, K.P., Hertig, E., Scheffran, J., 2012. Climate change, vulnerability and adaptation in North Africa with focus on Morocco. Agric. Ecosyst. Environ. 156, 12-26. https://doi.org/10.1016/j.agee.2012.04.021.

Schuster, M., Duringer, P., Ghienne, J.F., Vignaud, P., Mackaye, H.T., Likius, A., Brunet, M., 2006. The age of the Sahara desert. Science (80-. ) 311, 821. https://doi.org/10 1126 /science.1120161.

Schyns, J.F., Hoekstra, A.Y., 2014. The added value of water footprint assessment for national water policy: a case study for Morocco. PLoS One 9. https://doi.org/10. 1371/journal.pone.0099705.

Sheldon, F., Fellows, C.S., 2010. Temporal and spatial variability of water quality and water chemistry in two Australian dryland rivers. Mar. Freshw. Res. 61, 864-874.

Sheldon, F., Bunn, S.E., Hughes, J.M., Arthington, A.H., Balcombe, S.R., Fellows, C.S., 2010. Ecological roles and threats to aquatic refugia in arid landscapes: dryland river waterholes. Mar. Freshw. Res. 61, 885. https://doi.org/10.1071/MF09239.

Sophocleous, M., 2002. Interactions between groundwater and surface water: the state of the science. Hydrogeol. J. 10, 52-67. https://doi.org/10.1007/s10040-001-0170-8.

Sousa, R., Varandas, S., Teixeira, A., Ghamizi, M., Froufe, E., Lopes-Lima, M., 2016. Pearl mussels (Margaritifera marocana) in Morocco: conservation status of the rarest bivalve in African fresh waters. Sci. Total Environ. 547, 405-412. https://doi.org/10.1016/j. scitotenv.2016.01.003.

Sousa, R., Teixeira, A., Santos, A., Benaissa, H., Varandas, S., Ghamizi, M., Prié, V., Froufe, E., Lopes-Lima, M., 2018. Oued Bouhlou: a new hope for the Moroccan pearl mussel. Aquat. Conserv. Mar. Freshw. Ecosyst. 28, 247-251. https://doi.org/10. 1002/aqc. 2825.

Spooner, D.E., Frost, P.C., Hillebrand, H., Arts, M.T., Puckrin, O., Xenopoulos, M.A., 2013. Nutrient loading associated with agriculture land use dampens the importance of consumer-mediated niche construction. Ecol. Lett. 16, 1115-1125. https://doi.org/ 10.1111/ele.12146.

Stanley, E.H., Fisher, S.G., Grimm, N.B., 1997. Ecosystem expansion and contraction in streams. Bioscience 47, 427-435. https://doi.org/10.2307/1313058.

Strayer, D.L., Dudgeon, D., 2010. Freshwater biodiversity conservation: recent progress and future challenges. J. North Am. Benthol. Soc. 29, 344-358. https://doi.org/10. 1899/08-171.1.

Strayer, D.L., Downing, J.A., Haag, W.R., King, T.L., Layzer, J.B., Newton, T.J., Nichols, S.J., 2004. Changing perspectives on pearly mussels, North American's most imperiled animals. Bioscience 54, 429-439. https://doi.org/10.1641/0006-3568(2004) 054[0429:CPOPMN]2.0.CO;2.

Van Damme, D., 1984. The Freshwater Mollusca of Northern Africa. Distribution, Biogeography and Palaeoecology. Developments in Hydrobiology, the Netherlands.

Van Damme, D. \& Ghamizi, M. 2010a. Anodonta pallaryi. The IUCN Red List of Threatened Species 2010: e.T184606A8300644. https://doi.org/10.2305/IUCN.UK.2010-3. RLTS.T184606A8300644.en. Downloaded on 01 March 2019. doi:doi:https://doi. org/10.2305/IUCN.UK.2010-3.RLTS.T184701A8317425.en.

Van Damme, D., Ghamizi, M., 2010b. Unio foucauldianus. In: The IUCN Red List of Threatened Species 2010, e.T184708A8318610, doi:10.2305/IUCN.UK.20103.RLTS.T184708A8318610.en. Downloaded on 01 March 2019.

Vaughn, C.C., 2018. Ecosystem services provided by freshwater mussels. Hydrobiologia. https://doi.org/10.1007/s10750-017-3139-x.

Vaughn, C.C., Hakenkamp, C.C., 2001. The functional role of burrowing bivalves in freshwater ecosystems. Freshw. Biol. 46, 1431-1446. https://doi.org/10.1046/j 1365-2427.2001.00771x.

Walker, J.M., Bogan, A.E., Bonfiglio, E.A., Campbell, D.C., Christian, A.D., Curole, J.P., Harris, J.L., Wojtecki, R.J., Hoeh, W.R., 2007. Primers for amplifying the hypervariable, male-transmitted COII-COI junction region in amblemine freshwater mussels (Bivalvia: Unionoidea: Ambleminae): primer note. Mol. Ecol. Notes 7, 489-491. https://doi.org/10.1111/j.1471-8286.2006.01630.x. 